NBER WORKING PAPER SERIES

IMMIGRATION AND AFRICAN-AMERICAN EMPLOYMENT OPPORTUNITIES: THE RESPONSE OF WAGES, EMPLOYMENT, AND INCARCERATION TO LABOR SUPPLY SHOCKS

\author{
George J. Borjas \\ Jeffrey Grogger \\ Gordon H. Hanson \\ Working Paper 12518 \\ http://www.nber.org/papers/w12518
}

NATIONAL BUREAU OF ECONOMIC RESEARCH

1050 Massachusetts Avenue

Cambridge, MA 02138

September 2006

We thank Eli Berman, Melissa Famulari, and seminar participants at UCSD for helpful comments. The views expressed herein are those of the author(s) and $d$ not necessarily reflect the views of the National Bureau of Economic Research.

(C) 2006 by George J. Borjas, Jeffrey Grogger, and Gordon H. Hanson. All rights reserved. Short sections of text, not to exceed two paragraphs, may be quoted without explicit permission provided that full credit, including $\odot$ notice, is given to the source. 
Immigration and African-American Employment Opportunities: The Response of Wages, Employment, and Incarceration to Labor Supply Shocks

George J. Borjas, Jeffrey Grogger, and Gordon H. Hanson

NBER Working Paper No. 12518

September 2006, Revised May 2007

JEL No. J2,J3,J6,K42

\begin{abstract}
$\underline{\text { ABSTRACT }}$
The employment rate of black men, and particularly of low-skill black men, fell precipitously from 1960 to 2000. At the same time, the incarceration rate of black men rose markedly. This paper examines the relation between immigration and these trends in black employment and incarceration. Using data drawn from the 1960-2000 U.S. Censuses, we find a strong correlation between immigration, black wages, black employment rates, and black incarceration rates. As immigrants disproportionately increased the supply of workers in a particular skill group, the wage of black workers in that group fell, the employment rate declined, and the incarceration rate rose. Our analysis suggests that a 10-percent immigrant-induced increase in the supply of a particular skill group reduced the black wage by 4.0 percent, lowered the employment rate of black men by 3.5 percentage points, and increased the incarceration rate of blacks by almost a full percentage point.
\end{abstract}

George J. Borjas

Kennedy School of Government

Harvard University

79 JFK Street

Cambridge, MA 02138

and NBER

gborjas@harvard.edu

Jeffrey Grogger

Irving B. Harris Professor of Urban Policy

Harris School of Public Policy

University of Chicago

1155 E. 60th Street

Chicago, IL 60637

and NBER

jgrogger@uchicago.edu
Gordon H. Hanson

IR/PS 0519

University of California, San Diego

9500 Gilman Drive

La Jolla, CA 92093-0519

and NBER

gohanson@ucsd.edu 


\title{
IMMIGRATION AND AFRICAN-AMERICAN EMPLOYMENT OPPORTUNITIES: THE RESPONSE OF WAGES, EMPLOYMENT, AND INCARCERATION TO LABOR SUPPLY SHOCKS
}

\author{
George J. Borjas, Jeffrey Grogger, and Gordon H. Hanson*
}

\begin{abstract}
After a wave of raids by federal immigration agents on Labor Day weekend, a local chicken-processing company called Crider Inc. lost $75 \%$ of its mostly Hispanic 900-member work force. The crackdown threatened to cripple the economic anchor of this fading rural town. But for local African-Americans, the dramatic appearance of federal agents presented an unexpected opportunity. Crider suddenly raised pay at the plant. An advertisement in the weekly ForestBlade newspaper blared "Increased Wages" at Crider, starting at $\$ 7$ to $\$ 9$ an hour-more than a dollar above what the company had paid many immigrant workers. (The Wall Street Journal, January 17, 2007)
\end{abstract}

\section{Introduction}

The employment rate of African-American men-defined as the fraction of weeks worked during a calendar year by the typical black male-fell from 74.9 percent in 1960 to 67.9 percent in 2000. ${ }^{1}$ This drop stands in sharp contrast to the slight decline observed among white men during that period, from 87.0 to 85.2 percent. The racial employment gap widened even more for low-skill persons: the employment rate of black high school dropouts fell by 30 percentage points, from 72.1 to 42.1 percent, as compared to an 18 percentage point drop for white high school dropouts, from 82.7 to 64.3 percent.

The decline in labor market participation among black men was accompanied by a rapid increase in the number of black men in correctional institutions. As recently as 1980 , only 0.8 percent of black men (and 1.4 percent of black high school dropouts) were incarcerated. By

\footnotetext{
* Borjas: John F. Kennedy School of Government, Harvard University, and National Bureau of Economic Research; Grogger: Harris School of Public Policy Studies, University of Chicago, and National Bureau of Economic Research; Hanson: Graduate School of International Relations and Pacific Studies and Department of Economics, University of California, San Diego, and National Bureau of Economic Research. We thank Eli Berman, Donald Cox, Melissa Famulari, Peter Gottschalk, Richard Freeman, Larry Katz, and seminar participants at Boston College, Harvard University, and UCSD for helpful comments.

1 Throughout the paper, the "employment rate" gives the average fraction of weeks worked during the calendar year prior to the Census (i.e., the ratio of weeks worked, including zeros, to 52). The "incarceration rate" gives the fraction of persons who are institutionalized at the time of the Census. The data will be described in greater detail in the next section.
} 
2000, 9.6 percent of black men (and 21.2 percent of black high school dropouts) were incarcerated. $^{2}$

A large academic literature examines these trends. One strand of the literature emphasizes the impact of government programs, such as the Social Security disability program or the minimum wage, in driving black men out of the labor market (Bound and Freeman, 1992; Bound, Schauenbaum, and Waidmann, 1995; Parsons, 1980; Stern, 1989; and Welch, 1990). Another focuses on the possibility that the changes in the wage structure, and particularly the decline in the real wage of low-skill workers, may have discouraged low-skill black men from entering the labor market (Juhn, 1992, 2003). Finally, some analysts note that the trend in black incarceration rates was shaped by the crack epidemic of the 1980s and early 1990s. The invention of crack cocaine in the early 1980s represented a technological innovation that greatly increased the profitability of the cocaine trade. As illegal drug markets expanded, crime rose (Grogger and Willis, 2000). Many jurisdictions responded by increasing both drug arrests and the likelihood of imprisonment for convicted arrestees (Boggess and Bound, 1997). Crack and its consequences were concentrated in African-American communities, in part because pre-existing black gangs acted to profit from the expanding drug trade (Fryer et al, 2005).

Remarkably, as far as we know, no study has examined if there is a link between the resurgence of large-scale immigration and the employment and incarceration trends in the black population. ${ }^{3}$ Although it is well known that immigration has disproportionately increased the number of low-skill workers in the United States, there is disagreement over whether this influx has adversely affected competing native workers (Borjas, 2003; Card, 2001). The conflicting evidence hinges crucially on the nature of the empirical exercise: Studies that measure the impact of immigration by looking at wage trends across local labor markets tend to find small effects, while studies that examine the evolution of the national wage structure find large effects. Regardless of the geographic unit used to analyze the impact of immigration, any such impact would presumably be larger in the black workforce. In fact, some of the early studies in this

\footnotetext{
2 Western and Pettit (2000) show that ignoring the prevalence of incarceration rates provides a very misleading picture of employment trends in the black population.

${ }^{3}$ Using cross-section data from the 1980s, Butcher and Piehl (1998) find that metropolitan areas with larger immigrant populations had higher crime rates, but this relationship disappears once they control for the demographic characteristics of the underlying populations.
} 
literature (Borjas, 1987; Altonji and Card, 1991; and LaLonde and Topel, 1991) specifically attempted to measure the impact of immigration on black wages.

This paper examines the relation between immigration and black employment outcomes.

The empirical analysis shows that immigration has indeed lowered the wage of blacks. Our main interest, however, is on the behavioral consequences of this reduction of economic opportunities in the "formal" labor market. In particular, we investigate if the immigration-induced reduction in the black wage may have encouraged some black men to exit the labor force and shift to illegal activities. ${ }^{4}$

We use data drawn from the 1960-2000 U.S. Censuses. These data reveal a strong correlation between immigration and black wages, black employment rates, and black incarceration rates. As immigrants disproportionately increased the supply of workers in a particular skill group, we find a reduction in the wage of black workers in that group, a reduction in the employment rate, and a corresponding increase in the incarceration rate. Moreover, these correlations are found in both national-level and state-level data. In fact, our theoretical framework links the state- and national-level analysis and helps to resolve the conflict between the local and national studies in the literature. We show that the differences result from a remediable omitted-variable problem in the state-level regression. When the state-level regression is properly specified, it should (and, in fact, does) produce results that are very similar to those from the national-level regressions.

Our study suggests that a 10-percent immigrant-induced increase in the supply of a particular skill group is associated with a reduction in the black wage of 4.0 percent, a reduction in the black employment rate of 3.5 percentage points, and an increase in the black institutionalization rate of 0.8 percentage points. Among white men, the same ten-percent increase in supply reduces the wage by 4.1 percent, but has much weaker employment and incarceration effects: a 1.6 percentage point reduction in the employment rate and a 0.1 percentage point increase in the incarceration rate. It seems, therefore, that black employment and incarceration rates are much more sensitive to immigration than those of whites.

\footnotetext{
${ }^{4}$ We are aware of only one study that has linked immigration, wages, and incarceration rates. In their replication of the Borjas (2003) study, Raphael and Ronconi (2005) claim that adding incarceration rates as an explanatory variable in a regression of wages on immigrant shares attenuates the wage impact of immigration in national-level data. The Raphael-Ronconi empirical exercise, however, may have the logic backwards: shifts in incarceration rates are likely endogenous and may be partly caused by immigration.
} 
These findings can obviously generate a great deal of controversy in the immigration debate and can be easily misinterpreted. As a result, we are extremely cautious in both the presentation and interpretation of the evidence. Although we have attempted to control for other factors that may account for the large shifts in black employment and incarceration rates over the four-decade period that we examine, it should be obvious that no study can control for all possible factors. It is equally important to emphasize that although the evidence suggests that immigration played a role in generating these trends, much of the decline in employment or increase in incarceration in the black population remains unexplained. Put differently, immigration seems to have an effect and this effect seems to be numerically important, but we would have witnessed a sizable decline in black employment and the concurrent increase in black incarceration rates even if there had been no immigration in the past few decades.

\section{Data and Descriptive Trends}

Our data are drawn from the 1960, 1970, 1980, 1990 and 2000 Integrated Public Use Microdata Samples (IPUMS) of the decennial Censuses. The 1960 and 1970 files represent a 1 percent sample of the U.S. population, and the 1980 through 2000 files represent a 5 percent sample. In most of the paper, the empirical analysis is restricted to men aged 18 to 64 . The Data Appendix describes the construction of the sample extracts and variables used in the study.

We use the convention of defining an immigrant as someone who is either a noncitizen or a naturalized U.S. citizen. All other persons are defined as natives. Similarly, we use information contained in the census race variable to classify persons as "black" or "white." Unless otherwise specified, persons whose race is neither black nor white are excluded from the analysis.

As in Borjas (2003), skill groups are defined in terms of both educational attainment and years of labor market experience. We classify workers into four distinct education groups: (1) high school dropouts (workers who have less than 12 years of completed schooling); (2) high school graduates (workers who have exactly twelve years of schooling); (3) workers who have some college (thirteen to fifteen years of schooling); and (4) college graduates (workers who have at least sixteen years of schooling).

We group workers into a particular years-of-experience cohort by using potential years of experience, roughly defined by Age - Years of Education - 6. We assume that age of entry into the labor market is 17 for high school dropouts, 19 for high school graduates, 21 for persons with some college, and 23 for college graduates, and then calculate years of experience accordingly. 
The analysis is restricted to persons who have between 1 and 40 years of experience. Workers are aggregated into five-year experience groupings (i.e., 1 to 5 years of experience, 5 to 10 years, and so on) to capture the notion that workers who have roughly similar years of experience are more likely to affect each other's labor market opportunities than workers who differ significantly in their work experience. For national-level cohorts, the resulting data set contain 160 observations (4 education groups, 8 experience groups, and 5 years).

The cell corresponding to educational attainment $(e)$, experience level $(x)$, and calendar year $(t)$ defines a skill group at a point in time for the U.S. national labor market, or, later in the analysis, for a U.S. state labor market. The immigrant supply shock experienced by a particular skill group is given by:

$$
p_{e x t}=\frac{M_{e x t}}{M_{e x t}+N_{e x t}},
$$

where $M_{\text {ext }}$ gives the total number of immigrants in the workforce in the particular skill group; and $N_{\text {ext }}$ gives the corresponding number of native workers. ${ }^{5}$ The variable $p_{e x t}$ then gives the immigrant share (i.e., the fraction of the relevant workforce that is foreign-born).

Figure 1 summarizes some of the (well-known) information regarding trends in the immigrant share, by education and experience group, for the 1960-2000 period. The fraction of the workforce that is foreign-born increased most for high school dropouts. Within any given census year, the increase in the immigrant share is largest for workers with lower levels of labormarket experience, due to the preponderance of young adults in the immigrant population. By 2000, 14.7 percent of the male workforce and 39.8 of high school dropouts were foreign-born. Among high-school dropouts with 10 to 15 years of experience, 47.5 percent of the workforce was foreign born.

It is useful to begin our analysis by illustrating racial differences in national-level trends in employment and incarceration across race, education, and experience groups. ${ }^{6}$ The top panel

5 The counts of immigrants and natives in each Census include persons of all races.

6 To provide some context to the discussion, it is instructive to report the share of black and white workers in each of the education groups. In 2000, 18.8 (8.9) percent of blacks (whites) were high school dropouts, 43.7 (33.2) percent were high school graduates, 26.4 (29.0) percent had some college, and 11.1 (28.9) percent were college graduates. 
of Figure 2 reports the education-and-experience-specific trends for the black employment rate, while the bottom panel presents the corresponding figure for white men. As noted above, the employment rate is defined as the average fraction of weeks worked during the preceding calendar year (including non-workers). Both figures are drawn to the same scale so that the large racial differences can be grasped easily. Since employment rates and incarceration rates tend to be lower for men in their mid-50s or older, we mainly discuss the trends for those with up to 30 years of labor market experience.

In 1960 , the employment rate was 81.1 percent for black workers with at least a high school diploma and 1 to 30 years of labor market experience, and close to 80 percent for all but the youngest and oldest black high school dropouts. The relative similarity in employment rates among the various groups began to diverge in the 1970s. By 2000, the average employment rate of black high school dropouts was 40.5 percent, that of high school graduates was 64.4 percent, and that of workers who had more than a high school diploma was 80.9 percent (in each case for workers with 1 to 30 years of experience). While all black education groups had seen a drop in employment rates, the decline was most dramatic for the least educated.

The bottom panel of Figure 2 shows the corresponding trend for white men. As with blacks, there has been a decline in employment propensities for the least educated workers, but the decline is modest relative to that seen in the black population. Among the most educated whites, average employment rates remain very high for all but the oldest workers. For college graduates with up to 30 years of experience, the average employment rate was essentially flat during the four-decade period, at roughly 93 percent. Employment rates for black college graduates with similar experience levels actually rose slightly over the period from 86.4 percent to 87.7 percent. Among white high school dropouts with less than 30 years of experience, the average employment rate fell from 83.0 to 65.5 percent, a 17.5 percentage point drop. This is a large and important decline, although it is much smaller than the 32.7 percentage point drop observed among black high school dropouts with similar work experience.

The rapid disappearance of a large segment of black high school dropouts from the workforce was accompanied by a large increase in the number of black high school dropouts in the institutionalized population. We use information on residence in group quarters available in the decennial censuses to enumerate the number of persons in institutions. These institutions 
include jails, prisons, and mental hospitals. ${ }^{7}$ For young men, the 1980 Census shows that the majority of persons institutionalized are, in fact, incarcerated. Furthermore, the growth in institutionalization in Census data closely tracks the growth in incarceration apparent in Justice Department data from correctional facilities (Western and Pettit, 2000). For expositional convenience, therefore, we will refer to the fraction of persons institutionalized as the "incarceration rate."

Figure 3 presents the trends in the incarceration rate, by race, education, and experience, over the 1960-2000 period. We again use the same scale in the two graphs so that the very large racial differences can be easily seen. The average incarceration rate among white male high school dropouts with 1 to 30 years of experience increased from 1.2 to 6.4 percent between 1960 and 2000. For whites with at least a high school diploma, the incarceration rate remained small, even by 2000, when it reached 1.3 percent (and was slightly higher for younger men).

In contrast, the incarceration rate for black men increased rapidly beginning after 1980 for all groups except college graduates. Among high school dropouts with 1 to 30 years of experience, for example, the incarceration rate was 1.4 percent in 1960, 1.3 percent in 1980, 14.3 percent in 1990, and an astounding 25.1 percent in 2000. Even among blacks with a high school diploma, the incarceration rate for those with 1 to 30 years of experience rose from 0.5 percent in 1980 to 9.8 percent in 2000 .

The question at the core of this paper examines whether these trends are related to the increases in immigration experienced by the specific skill cohort at a particular point in time. To visually illustrate the nature of this link, Figure 4 presents a scatter diagram relating decadal changes in the immigrant share and decadal changes in employment rates for blacks and whites, after removing decade effects. Figure 5 presents the corresponding scatter diagrams relating decadal changes in the immigrant share and decadal changes in incarceration rates. By removing decade effects, we control for features of the economic environment that are common to all education and experience groups in any given decade, but that might vary over time.

The graphical evidence is striking. Each point in the scatter diagram in Figure 4 represents the change in employment rate for an $(e, x, t)$ cell and the corresponding change in the immigrant share of the workforce for that cell. It is evident that there is a negative correlation

\footnotetext{
7 Although it is possible to differentiate between correction facilities and mental hospitals before 1990, there is no such information in the 1990 and 2000 census data. To keep the variable definitions constant over time, we focus on the number of persons who are in institutions.
} 
between changes in employment propensities and the immigrant share, and that the correlation is stronger for black men. Similarly, Figure 5 shows a corresponding positive correlation between changes in incarceration rates and the immigrant share, with the correlation again being stronger for black men. The remainder of this paper examines if these correlations persist after we control for other factors that affected the trends in male employment and incarceration propensities over this time period.

\section{Theory}

To understand how immigration could reduce employment and increase incarceration among native-born persons, with possibly larger effects among African-Americans, consider a two-sector model of a national labor market. Native labor consists of black and white workers, who are perfectly mobile between a formal sector (i.e., the "market" sector) and a sector dedicated to crime.

It is instructive to consider one particularly simple specification of this model. Suppose the market sector employs both natives and immigrants, with all workers being perfect substitutes in terms of their contribution to output. ${ }^{8}$ The crime sector employs only native workers. Further, the demand for labor in the crime sector is race-specific, with black and white workers having separate crime production functions. Finally, native labor supply to the market and crime sectors is endogenous, with individuals choosing to increase leisure and participation in crime and to reduce market work as the wage in the market sector falls.

We use this framework to investigate the consequences of an exogenous shift in the supply of immigrant labor. We are interested in determining whether immigration induces some native workers to exit market employment and enter the crime sector. The mechanism through which this might occur is straightforward. A positive immigrant supply shift puts downward pressure on the wage in the market sector, causing native workers to substitute out of market work and into either crime or leisure. Intuitively, the more elastic is either the demand for criminal labor or the demand for leisure, the larger is the reduction in market employment and the smaller is the reduction in the equilibrium wage. Hence immigration is associated with either large wage effects and small market-sector employment effects, or the converse, depending on the relevant elasticities. One can think of the model as a general-equilibrium extension of Gronau

\footnotetext{
${ }^{8}$ The race of immigrant workers is left unspecified.
} 
(1977), in which individuals allocate time between work, leisure, and home production. Our framework reinterprets home production as crime (as in Grogger, 1998) and endogenizes the wage. ${ }^{9}$

The specification of the model presented in this section relies on three key assumptions. First, we assume that all labor types are perfect substitutes in the market sector. Although the assumption of perfect substitutability is not essential for deriving our theoretical results, it greatly simplifies the analysis. ${ }^{10}$ More important, we can easily test for the validity of this assumption using the data set of 160 cells (defined by education, experience, and time) introduced in the previous section. In particular, we use a nested CES framework to derive estimable relative labor demand functions that relate the relative price of a labor group to the relative quantity of that group. ${ }^{11}$ It is well known that the coefficient of the relative quantity variable in this type of regression model estimates the parameter $-1 / \sigma$, where $\sigma$ is the elasticity of substitution between the groups. The top panel of Table 1 reports the estimated coefficient that examines the extent of substitutability between black and white native labor (i.e., the dependent variable is the log wage ratio between black and white workers and the independent variable is the log ratio of the number of black to white workers). The results do not provide any support for the hypothesis that

\footnotetext{
${ }^{9}$ The resulting framework is similar to the specific-factors model of a small open economy (Feenstra, 2004), extended to allow for the endogenous supply of labor to wage employment.

${ }^{10}$ In unreported theoretical results, we solved a model in which black, white, and immigrant labor are imperfect substitutes in the production of formal-sector output. All of the qualitative results of the simpler model presented here carry through to the more general framework (one minor difference is that imperfect substitutability produces slightly different estimating equations than those reported below in (6a)-(6d)). The derivation of the more general model is available on request.
}

11 Consider a generic two-level nested CES production function (as in Card and Lemieux, 2001), where the first level defines the size of the native-born workforce as a CES aggregate of the number of black $(b)$ and white $(w)$ workers, and the second level defines output as a function of the (CES-weighted) native-born workforce and immigrants. By equating the wage to the marginal product of labor for each native worker type, it is easy to derive the relative demand function:

$$
\ln \left(w_{b s t} / w_{w s t}\right)=-\frac{1}{\sigma} \ln \left(N_{b s t} / N_{w s t}\right)+\frac{1-\sigma}{\sigma} \ln \left(\tau_{b s t} / \tau_{w s t}\right)
$$

where $\sigma$ is the elasticity of substitution between black and white native workers; $w_{i s t}$ is the wage of race group $i$ and skill group $s$ at time $t ; N_{i s t}$ is employment; and $\tau_{i s t}$ is a parameter measuring relative efficiency. In Table 1, we proxy the relative efficiency terms by a vector of fixed effects indicating education, experience, and time effects, and their interactions, and a random error term. The null hypothesis of perfect substitution states that the coefficient $-1 / \sigma$ equals zero. Once we establish that black and white native workers are perfect substitutes, it is trivial to jump to the next level of the nested CES system and derive an analogous equation giving the relative wage of immigrants as a function of the relative number of immigrants. 
black and white workers are imperfect substitutes (within these narrowly defined skill groups). Similarly, the bottom panel of the table reports the estimated coefficient from regressions of the relative wage of immigrant workers on their relative quantity (i.e., the dependent variable is the log wage ratio between immigrant and native workers and the independent variable is the log quantity ratio). Again, there is no evidence to support the hypothesis that immigrants and natives are imperfect substitutes. ${ }^{12}$ For the remainder of the analysis, therefore, we will maintain the assumption that different labor types (within the narrow education-experience categories) are perfect substitutes.

We also assume that immigrants do not participate in crime. One could generalize the model to allow immigrant labor to be employed in either the market or crime sector. Our results would hold as long as the elasticity of labor demand in crime is larger for natives than immigrants (or, alternatively, if the elasticity of substitution between native and immigrant labor is higher in market employment than in crime). Since criminal penalties are larger for immigrants than natives (for non-citizens, the penalties for criminal activity are incarceration and possible deportation), it seems reasonable to assume immigrants are less likely than natives to substitute into crime in response to a negative wage shock. In fact, relative to observationally equivalent natives, immigrants are much less likely to be incarcerated and more likely to work (Butcher and Piehl, 1998, 2000).

Finally, we assume that there are race-specific crime production functions, effectively implying that black and white criminals tend to operate in separate markets. ${ }^{13}$ This assumption allows immigration to have different effects by race. Black men, by virtue of being relatively concentrated in inner cities, may have more opportunities to engage in criminal activity. Grogger (1998) finds that black men are more likely to participate in crime than white men even after controlling for alternative labor market options. Further, black-white differences in criminal propensities may have been exacerbated by the advent of crack cocaine. Fryer et al (2005) argue that pre-existing gang organizations, which controlled street corners and other outdoor spaces in many urban areas, gave blacks an advantage in creating and controlling crack distribution

12 The literature provides mixed evidence on the extent of substitution between immigrant and native workers (Cortes, 2005; Jaeger, 1996; and Ottaviano and Peri, 2006).

13 This assumption, like the other two, simplifies the discussion but is not essential for the results. What is essential for immigration to have different effects on black and white workers is that the elasticity of labor demand in crime differs between the two groups. 
networks. ${ }^{14}$ Other evidence suggests criminal gangs tend to be organized along racial lines and operate in spatially segmented markets (Venkatesh, 1997; Grogger and Willis, 2000).

Let $L_{f s}=N_{b f s}+N_{w f s}+M_{s}$, where $N_{b f s}$ denotes employment of native black workers in the (formal) market sector who have skill $s ; N_{w f s}$ denotes the corresponding employment of native white workers; and $M_{s}$ denotes the corresponding number of immigrants. For workers of race $i$ and skill group $s$, the wage in the market sector is:

$$
w_{i s}=X_{f s}\left(1-\delta_{i}\right)\left(L_{f s}\right)^{\eta_{f}} \text {, }
$$

where $X_{f s}$ is a labor demand shifter for the market sector; $\delta_{i}$ is a parameter that captures preferences for discrimination on the part of employers, with $\delta_{w}=0$ and $1>\delta_{b} \geq 0$, so that black workers may face a lower market wage as a result of discrimination; and $\eta_{f}<0$ is the inverse of the labor demand elasticity in the market sector (or the factor price elasticity in this simple framework). Equation (2) assumes that all workers in skill group $s$ are perfect substitutes in terms of their contribution to market sector output.

The marginal product of labor in the crime sector for workers in racial group $i$ with skill $s$ is:

$$
w_{i s}=X_{i c s}\left(N_{i c s}\right)^{\eta_{i c}}
$$

where $X_{i c s}$ is a demand shifter for criminal activity, $N_{i c s}$ gives employment of native workers of race $i$ and skill group $s$ in crime, and $\eta_{i c}<0$ is the inverse of the labor demand elasticity in the crime sector.

Black-white wage differences are determined by the extent of discrimination in the market sector, with $w_{b} / w_{w}=\left(1-\delta_{b}\right) \leq 1 .{ }^{15}$ Inter-sectoral labor mobility transmits the discrimination-driven market racial wage gap to the crime sector. The demand shifters, $X_{f s}$ and $X_{i c s}$, embody capital, TFP, and the output price in each sector. Our empirical analysis will allow

\footnotetext{
14 Responses to a survey of 27 large-city police chiefs administered by Grogger and Willis (2000) indicated that crack was concentrated among blacks or minorities in all but four jurisdictions.
} 
for changes in sectoral demand shifters by controlling for race-specific changes in the returns to skill over time.

The supply of labor to paid employment (i.e., employment in either the market or crime sectors) is elastic, with the inverse demand for leisure given by:

$$
w_{i s}=X_{i h s}\left(N_{i h s}\right)^{\eta_{i h}}
$$

where $X_{i h s}$ is a leisure demand shift parameter, $N_{i h s}$ gives the number of natives consuming leisure, and $\eta_{i h}<0$ is the inverse of the demand elasticity for leisure.

Finally, the allocation of native labor to employment in the market sector, employment in the crime sector, and leisure is subject to the constraint:

$$
\tilde{N}_{i s}=N_{i f s}+N_{i c s}+N_{i h s},
$$

where $\tilde{N}_{i s}$ is the (constant) population of native-born persons of race $i$ and skill $s$.

Equations (2)-(5) represent a system of seven equations in seven unknowns. For simplicity, we neglect the impact of immigration on capital accumulation, which would tend to dampen the wage effects of immigration over time. ${ }^{16}$ Figure 6 illustrates the equilibrium of the model for black workers of skill group $s$. There is an analogous, and interdependent, set of equilibrium conditions for white workers. The equalization of wages for black workers between the formal sector and the crime sector is shown by the intersection of the two sectoral labor demand schedules at point 1 . The allocation of labor to leisure is implicit, since the endogenous leisure allocation defines the value $\tilde{N}_{b s}-N_{b h s}=N_{b c s}+N_{b f s}$, which is total black labor available for employment in either the market or crime sector. Solving for $N_{b h s}$ defines the width of the

\footnotetext{
15 For simplicity, we assume that the discrimination coefficient is independent of skills. Relaxing this assumption does not change any of the results of the model.

16 We have worked out an extension of the model where the market sector employs both labor and capital in production, with the supply of capital adjusting over time in response to deviations in the return to capital from its long-run rate. As long as complete adjustments in the capital stock are not immediate, the short-run consequences of immigration are qualitatively the same as those implied by the simpler model summarized in this section. The model is available on request from the authors.
} 
box in Figure 6. The sensitivity of leisure to wages will become apparent once we consider a labor-supply shock due to immigration.

Figure 7 shows the labor-market consequences of an increase in immigrant labor supply. The immediate direct effect is a contraction in the demand for native labor. ${ }^{17}$ The contraction in market-sector labor demand puts downward pressure on the market wage, inducing native labor to increase leisure and decrease labor supplied to the market. The increase in leisure implies that labor available for either the market or crime sectors falls from $\tilde{N}_{b s}-N_{b h s}$ to $\tilde{N}_{b s}-N_{b h s}^{\prime}$, which implies the right vertical axis in Figure 7 shifts to the left, inducing a corresponding leftward shift, from $D_{c}$ to $D_{c}^{\prime}$, in the demand for labor in the crime sector (whose horizontal position is determined by the position of the right axis).

The net effect of the immigrant labor supply shock is a new equilibrium at point 2 , in which the black wage is lower, black employment in the market sector is lower, black employment in the crime sector is higher, and black leisure is higher. Market employment falls because immigrant labor substitutes for black labor; black employment in crime rises because lower market-sector labor demand induces blacks to shift into crime; and black leisure rises because the black wage falls.

The model has similar qualitative predictions for the wage and sectoral distribution of white workers. The model, in addition, yields an important and testable quantitative prediction. Since black and white workers are perfect substitutes in the market sector, the percent impact of immigration on the black and white wage is the same. As long as the discrimination parameter $\delta_{b}$ is invariant to labor-market conditions, immigration changes black and white wages by the same percentage amount, leaving the racial wage differential unchanged. However, racial differences in the demand elasticities of crime and leisure imply that the employment effects of immigration need not have the same magnitude.

Let $w_{i s}^{*}$ be the wage for race group $i$ and skill group $s$ in the pre-immigration equilibrium, and let $N_{f s}^{*}$ give the corresponding number of native workers in the market sector at that time $\left(N_{f s}^{*}=N_{b f s}^{*}+N_{w f s}^{*}\right)$. We measure the immigrant supply shock by $m_{s}=M_{s} / N_{f s}^{*}$, the immigrantinduced percent increase in labor supply to the market sector. Part 1 of the Mathematical

\footnotetext{
17 For black workers, part of the inward shift in formal-sector labor demand is mitigated by the exit of white workers from the formal sector. In the graphical analysis, this adjustment is implicit.
} 
Appendix shows that the race-specific equations relating post-immigration wages, native labor allocations, and the immigrant supply shock are given by:

$$
\begin{aligned}
& \ln w_{i s}=\ln w_{i s}^{*}+\eta_{f} \rho m_{s}, \\
& \ln N_{i c s}=\ln N_{i c s}^{*}+\frac{\eta_{f} \rho}{\eta_{i c}} m_{s}, \\
& \ln N_{i h s}=\ln N_{i h s}^{*}+\frac{\eta_{f} \rho}{\eta_{i h}} m_{s}, \\
& \ln N_{i f s}=\ln N_{i f s}^{*}-\frac{\eta_{f} \rho}{\theta_{i f s}}\left(\frac{\theta_{i c s}}{\eta_{i c}}+\frac{\theta_{i h s}}{\eta_{i h}}\right) m_{s} .
\end{aligned}
$$

As shown in the Appendix, the parameter $\rho$ is a positive constant that lies between zero and one and is defined by:

$$
\rho=\frac{\bar{N}_{f}}{\bar{N}_{f}+\frac{\eta_{f}}{\eta_{b c}} \bar{N}_{b c}+\frac{\eta_{f}}{\eta_{w c}} \bar{N}_{w c}+\frac{\eta_{f}}{\eta_{b h}} \bar{N}_{b h}+\frac{\eta_{f}}{\eta_{w h}} \bar{N}_{w h}},
$$

where $\bar{N}_{j}$ is the average number of type-j natives across skill groups in the pre-immigration equilibrium.

The parameter $\rho$ gives an elasticity-adjusted measure of the market sector participation rate of natives in the pre-immigration equilibrium. Consider, for instance, the special case where the demand elasticities are equal in all activities, so that $\eta_{f}=\eta_{i c}=\eta_{i h}$. Equation (7) shows that $\rho$ is then exactly equal to the fraction of natives participating in the market sector in the preimmigration period. It is also worth noting that if the demand for labor in both the crime and leisure sectors is perfectly inelastic (so that the ratios $1 / \eta_{i c}$ and $1 / \eta_{i h}$ are equal to zero), the parameter $\rho$ is then equal to one. In this extreme case, the relative number of native workers in each of the sectors is effectively fixed.

Equation (6a) implies that more immigration lowers wages $\left(\eta_{f} \rho<0\right)$, with the wage impact being greater the larger the factor price elasticity in the market sector. Two points are worth emphasizing about the wage impact of immigration. First, as noted above, the wage 
impact is predicted to be the same for black and white workers. ${ }^{18}$ Second, the reduced-form regression of the log wage on the immigrant supply shock $m$ does not identify the factor price elasticity, $\eta_{f}$. Rather, it identifies the product of the factor price elasticity and $\rho$, the parameter that roughly indicates the sectoral allocation of the native population (up to a linear approximation). As noted above, $\rho$ equals one when the supply of native labor to the market sector is perfectly inelastic. It is only in this case that the regression coefficient identifies the factor price elasticity. If native labor supply to the market sector is elastic, however, the reducedform impact of immigration is numerically smaller than the factor price elasticity. The intuition for this result is obvious: Native opportunities to substitute into crime or leisure dampen the impact of immigration on the market wage, relative to the case of inelastic labor supply. Figure 7 illustrates the result. If the demand for leisure were perfectly inelastic the post-immigration equilibrium would be at point 1 , instead of point 2 . The fall in the native wage would be larger and the fall in native formal employment would be smaller. We will refer to the product $\eta_{f} \rho$ as the "reduced-form wage elasticity."

Equation (6b) shows that a larger immigrant supply shock increases the number of natives participating in the crime sector $\left(\eta_{f} \rho / \eta_{i c}>0\right)$, with the impact of immigration being larger the more elastic is the demand for crime labor relative to the demand for formal labor. The immigration-induced change in crime employment for blacks relative to whites depends on the ratio of the elasticities $\eta_{w c} / \eta_{b c}$. Even though the wage impact of immigration is predicted to be the same for blacks and whites, black employment in the crime sector is more responsive to immigration if the elasticity of labor demand in crime is larger for blacks than whites.

Equation (6c) indicates that more immigration is associated with greater native demand for leisure $\left(\eta_{f} \rho / \eta_{i h}>0\right)$, with the impact of immigration on leisure being larger the more elastic is the demand for leisure relative to the demand for formal labor. Similar to participation in crime, the immigration-induced change in leisure for blacks relative to whites depends on the ratio of elasticities $\eta_{w h} / \eta_{b h}$, indicating that black leisure time is more responsive to immigration if the elasticity of demand for leisure is larger for blacks than whites.

\footnotetext{
18 As shown by equation (2), the market sector wage for both black and white workers (who are perfect substitutes in production) is determined by the equilibrium size of the workforce in that sector. As a result, the manner in which native substitution across sectors mitigates the wage consequences of immigration is common to all native workers, regardless of race.
} 
Finally, equation (6d) implies that a larger immigrant supply shock is associated with lower native market sector employment, with the impact of immigration being larger the more elastic is the demand for formal labor relative to the demands for crime labor or leisure. The impact of immigration depends on the pre-existing employment shares in the various sectors, where $\theta_{i c s}=N_{i c s}^{*} / \tilde{N}_{i s}$ (the pre-immigration share of race $i$ persons in the crime sector), $\theta_{i h s}=N_{i h s}^{*} / \tilde{N}_{i s}$ (the pre-immigration share of race $i$ persons in the leisure sector), and $\theta_{i f s}=N_{i f s}^{*} / N_{i s}^{\%}$ (the pre-immigration share of race $i$ persons in the market sector). ${ }^{19}$ If, for expositional convenience, we ignore the skill subscript, equation (6d) implies that the change in market employment for blacks relative to whites is given by the ratio $\theta_{w f}\left(\theta_{b c} / \eta_{b c}+\theta_{b h} / \eta_{b h}\right) /$ $\theta_{b f}\left(\theta_{w c} / \eta_{w c}+\theta_{w h} / \eta_{w h}\right)$, which shows that black market employment is more responsive to immigration if the elasticities of demand for crime labor and for leisure are larger for blacks than whites (as long as the market participation rate of whites is at least as high as that of blacks). ${ }^{20}$

This model helps us understand the source of racial differences in the consequences of immigration and motivates why the empirical analysis presented in the subsequent sections allows the impact of immigration on wages, employment, and incarceration rates to differ between black and white men. As we have seen, if the demand for labor in the crime sector is more elastic for blacks than for whites, immigration will have a larger negative impact on black market employment and a larger positive impact on black crime employment. A similar qualitative effect on market employment, but not for crime employment, would result if the demand for leisure were more elastic among blacks than whites.

Our empirical analysis uses data on wage and employment rates for education-experience cohorts by year. Although we do not have data on participation rates in crime, we do have information on incarceration rates for the various groups. ${ }^{21}$ These data constraints require that we

\footnotetext{
${ }^{19}$ Note that none of the coefficients in equations (6a)-(6d) depend on the extent of discrimination in the labor market because the discrimination coefficient is assumed to be constant over time.

20 The condition for immigration to affect black market sector employment more than for whites depends on initial black-white relative employments in crime and leisure. If the initial black shares of employment in crime and leisure are higher than the white shares $\left(\theta_{b c}>\theta_{w c}, \theta_{b h}>\theta_{w h}\right)$, immigration can then induce relatively larger reductions in market sector employment for blacks even if the black crime and leisure demand functions are less elastic than those for whites.

21 The National Longitudinal Survey of Youth (NLSY) has information on participation in criminal activities, but only for a single cross-section.
} 
estimate the reduced-form expressions, as summarized by equations (6a)-(6d), rather than a structural model of sectoral time allocation.

\section{National Level Evidence}

Let $y_{\text {ext }}$ denote the mean value of a particular labor market outcome for native-born men who have education $e$, experience $x$, and are observed at time $t$. As noted above, we calculated $y_{\text {ext }}$ using the sample of natives who are either black or white. The empirical analysis reported in this section stacks these national-level data across skill groups and calendar years and estimates the following regression model separately by race:

$$
y_{\text {ext }}=\theta p_{\text {ext }}+E+X+T+(E \times T)+(X \times T)+(E \times X)+\varphi_{\text {ext }}
$$

where $E$ is a vector of fixed effects indicating the group's educational attainment; $X$ is a vector of fixed effects indicating the group's work experience; and $T$ is a vector of fixed effects indicating the time period. The linear fixed effects in equation (8) control for differences in labor market outcomes across schooling groups, experience groups, and over time. The interactions $(E \times T)$ and $(X \times T)$ control for the possibility that the impact of education and experience changed over time, and the interaction $(E \times X)$ controls for the fact that the experience profile for a particular labor market outcome may differ across education groups. The regression specification in (8) implies that the labor market impact of immigrant-induced labor supply shifts is identified using time-variation within education-experience cells. Unless otherwise specified, the regressions are weighted by the number of observations used to calculate the dependent variable $y_{\text {est }}{ }^{22}$ The estimated coefficients are generally similar to those obtained from unweighted regressions. Finally, the standard errors are clustered by education-experience cells to adjust for possible serial correlation.

We examine the impact of immigration on three distinct outcomes. The alternative dependent variables include: the log weekly earned income, the employment rate, and the

\footnotetext{
22 We normalized the sum of weights to equal 1 in each cross-section to prevent the latter censuses from contributing more to the estimation simply because the U.S. population increased over time.
} 
incarceration rate. ${ }^{23} \mathrm{We}$ estimate the employment and incarceration rate regressions using a grouped logit estimator. ${ }^{24}$ Let $r_{e x t}$ be the relevant employment or incarceration rate for cell (e, $x$, $t$ ). The grouped logit estimator is given by the weighted least squares regression of the log odds model:

$$
\ln \left(\frac{r_{\text {ext }}}{1-r_{\text {ext }}}\right)=\theta^{*} p_{\text {ext }}+E+X+T+(E \times T)+(X \times T)+(E \times X)+\varphi_{e x t} .
$$

To make the results more easily interpretable, we convert the estimated coefficient $\theta^{*}$ (and its standard error) into a marginal impact, which is given by $\theta^{*} \bar{r}(1-\bar{r})$, where we use the racespecific sample mean of the employment (or incarceration) rate in the calculation. ${ }^{25}$

It is important to emphasize that the incarceration rate is an imperfect measure of participation in crime, as individuals in prison today may have committed crimes several or more years in the past when different labor market conditions prevailed. To control for lags between shocks to the labor market and changes in the size of the prison population, we report results on incarceration that use either the current share of immigrants in the workforce or the five-year lag of the immigrant share. Together, the contemporaneous immigrant share and the five-year lag bracket the length of the average prison term, which is about two years (Raphael and Stoll, 2005).

Table 2 reports our estimates of the adjustment coefficient $\theta$ (or the corresponding marginal impact in the grouped logit regressions). The top panel of the table reports the least squares estimates of the regression model. The first row of the panel reports the results for black men, while the second row reports the results for white men. Consider initially the results when the dependent variable is the mean log weekly earnings of the skill group $(e, x, t)$. The

\footnotetext{
${ }^{23}$ Recall that the employment rate is defined by the average fraction of weeks worked during the calendar year prior to the Census (including non-workers).

24 The use of logit versus a linear probability model leads to relatively similar marginal impacts for the employment rates, but smaller marginal impacts for the incarceration rate. This is not surprising given the clustering of incarceration rates at very small numbers near zero.

25 The weighted least squares estimator for grouped logit uses a weight equal to $n_{\text {ext }} \hat{r}_{\text {ext }}\left(1-\hat{r}_{\text {ext }}\right)$, where the predicted probabilities are calculated from a first-stage unweighted regression on the log odds ratio and $n_{\text {ext }}$ is the sample size in the cell.
} 
adjustment coefficient $\theta$ is -0.561 (with a standard error of 0.167 ) for blacks, and $-0.669(0.250)$ for whites. These coefficients are easier to interpret if we convert them into an elasticity that gives the percent change in wages associated with a percent change in labor supply. Let $m_{\text {ext }}=$ $M_{e x t} / N_{e x t}$, or the percentage increase in the labor supply of group $(e, x, t)$ attributable to immigration. We can calculate the reduced-form wage effect (equivalent to the product of parameters $\eta_{f} \rho_{f}$ in our theoretical framework) as:

$$
\frac{\partial \log w_{e x t}}{\partial m_{e x t}}=\theta\left(1-p_{e x t}\right)^{2} .
$$

By 2000, immigration had increased the immigrant share in the U.S. workforce to 14.7 percent. Equation (9) implies that the reduced-form wage elasticity-evaluated at the mean value of the immigrant supply shift as of 2000 — can be obtained by multiplying $\theta$ by approximately 0.73 . The reduced-form wage elasticity for weekly earnings is then -0.41 (or $-0.561 \times 0.73$ ) for blacks, and -0.49 for whites. Put differently, a 10 percent immigrant-induced increase in the number of workers in a particular skill group reduces the wage of that group by 4 to 5 percent. ${ }^{26}$ These results closely match the estimated wage impacts of immigration across all workers reported in Borjas (2003). Note that the similarity in the wage effects between the two race groups provides additional evidence supporting the hypothesis that black and white native workers (within narrowly defined skill groups) are perfect substitutes in production.

Columns two through four of Table 2 show the relation between immigration and employment and incarceration rates. There is a strong negative relation between immigration and employment rates and a strong positive relation between immigration and incarceration rates. A 10 percent increase in supply is predicted to reduce the employment rate of black men by 3.6 percentage points $(-0.489 \times 0.73)$ and that of white men by 1.5 percentage points. Similarly, a 10 percent increase in supply increases the incarceration rate of black men by 0.7 percentage points and that of white men by 0.1 percentage points (although the impact on whites is not significant).

\footnotetext{
26 The regression model in (7) uses the immigrant share, $p$, rather than the (more natural) relative number of immigrants, $m$, as the regressor. The main reason for using $p$ as the regressor is that the outcomes used in this paper tend to be nonlinearly related to $m$, and $p$ is approximately a linear function of $\log m$. Rather than introducing significant nonlinearity in the regression, we opted for the simpler approach of a generic regression of the outcome on the immigrant share.
} 
Lagged immigration has a similar effect on incarceration rates for blacks and a somewhat larger (and now statistically significant) effect on whites. It seems, therefore, that the impact of immigration at the extensive margin of labor supply is far larger for blacks than for whites.

One potential problem with these least squares estimates is that the immigrant share included in the right-hand-side of equation (7) - that is, the fraction of the workforce that is foreign-born - may be endogenous. Only those persons (both immigrant and natives) who find it worthwhile to remain in the workforce are included in the counts, and hence there may be some correlation between the immigrant share and the disturbance term. Although our theoretical model maintained the assumption of inelastic immigrant labor supply, it would be desirable to relax that assumption in the empirical work.

We use instrumental variables to correct for the possible endogeneity bias, where the instrument is the immigrant share in the population. Panel B of Table 2 reports the estimated IV coefficients. The wage effects from the IV specification are similar to those from the least squares regression. The least squares coefficient of the immigrant share on the log weekly wage of black men, for example, is -0.561 (0.167), while the corresponding IV coefficient is -0.519 (0.172). In addition, the estimated IV coefficients in the black employment and black incarceration regressions are essentially the same as those obtained in the least squares specification.

Another important issue is that the measured effects of immigration on labor market status may be contaminated by factors that are driving employment and incarceration behavior for blacks and whites within education-experience groups. These factors will not be absorbed by the fixed effects included in the regression and may be correlated with the immigrant supply shifts. The potential existence of these additional factors is not altogether surprising. As we discussed above, the wage structure changed considerably during our sample period and the crack epidemic raised the return to crime during the 1980s and 1990s. It is important, therefore, to examine the impact of various sources of bias on the magnitude of the estimated coefficients.

Consider initially how the crack epidemic may influence our estimated correlations. In terms of the model from the previous section, the invention of crack raises the marginal product of criminal labor, shifting the curve labeled $D_{c}$ in Figure 6 to the left. This leftward shift reduces native labor supplied to the formal sector and raises native labor supplied to crime, just like an increase in immigration. Unlike an increase in immigration, however, the increasing productivity of crime should raise equilibrium wages. This casts some doubt on the notion that the effects we 
attribute to immigration are entirely due to crack, since we showed empirically that immigration reduced wages. Nevertheless, given the potential importance of crack as an alternative explanation, it is important to account for it explicitly in the regression model.

To do so we make use of the "crack index" developed by Fryer, Heaton, Levitt, and Murphy (2005). This index is a linear combination of several variables related to the crack epidemic, including the share of arrests made for cocaine-related charges, the number of deaths due to cocaine, the number of cocaine busts carried out by the federal Drug Enforcement Administration, and the number of cocaine-related hospital emergency room incidents. Most of these measures can obviously be considered as outcomes of the crack epidemic, whereas the ideal measures for our purposes would be indicators of the extent to which crack raised criminal productivity and exogenous measures of the criminal-justice response to the crack problem. Thus one could argue that the crack index is really an endogenous variable, particularly in the incarceration regressions. This possibility will affect the interpretation of our results.

The Fryer et al crack index varies only by time and race, meaning that its main effects are subsumed by the year fixed effects included in our regression model. ${ }^{27}$ To include the index in the model, we interact it with the education-experience fixed effects. In particular, consider the following regression:

$$
y_{\text {ext }}=\theta p_{\text {ext }}+E+X+T+(E \times T)+(X \times T)+(E \times X)+(E \times X) C_{t}+\varphi_{\text {ext }},
$$

where $C_{t}$ is the value of the crack index at time $t$. Note that the specification in (10) essentially introduces a specific type of time variation in the education-experience interaction fixed effects. Obviously, a totally unrestricted type of variation would be impossible since there would then be as many education-experience-time interactions as there are observations. Our specification permits the effects of skill to vary over time in a manner that is related to the spread of crack, while still enabling us to estimate the effects of immigration from changes over time within the same skill groups.

The estimated adjustment coefficients $\theta$ (and corresponding marginal impacts in the grouped logit regressions) are reported in panel $\mathrm{C}$ of Table 2. It is evident that our estimated

\footnotetext{
27 The index takes on a value of 0 for all cells drawn from the 1960, 1970, or 1980 Censuses. The index for the 1990 cells is the average for 1988 and 1989 of the Fryer et al (2005) race-specific city-level crack index. The index for the 2000 cells is the average of the 1998 and 1999 values.
} 
marginal effects on black wages, employment, and incarceration rates are not very sensitive to the inclusion of the crack index. A ten-percent immigrant-induced supply shift still lowers the wage of blacks by -4.2 percent, lowers the employment rate by 3.1 percentage points, and increases the incarceration rate by 0.7 percentage points.

There is an important sense in which the Fryer et al crack index does not capture how the crack epidemic affected the sectoral choices of the various skill groups. The index, after all, takes on the same value for black high school dropouts as it does for black college graduates. It is evident that the crack epidemic had a much greater impact on the behavior of low-skill (and younger) persons. To incorporate this notion into our study, we re-estimated the regression models using a "restricted" version of the Fryer et al crack index. In particular, we reset the index to 0 for all persons who have at least a high school diploma or more than 20 years of work experience. The restricted crack index, therefore, effectively assumes that the crack epidemic was mainly a demand shifter for younger, low-skill persons.

Panel D of Table 2 reports the regression coefficients obtained from the use of the restricted crack index. Note that this change in the way we account for the crack epidemic barely affects our results.

The use of the crack index helps the regression model partly account for what has been happening at the low-skill end of the U.S. labor market. A large research literature documents that there was also a substantial increase in the rate of return to skills and to labor market experience beginning around 1980 (Katz and Murphy, 1992; Autor, Katz, and Kearny, 2005).

Our basic regression specification in equation (7) attempts to control for these changes by including interactions of fixed effects between education and time, as well as interactions of fixed effects between experience and time. As noted above, ideally we would control for changes in the wage structure by including a complete set of three-way interactions between the education, experience, and time fixed effects. Such a strategy is not feasible, however, because the full set of interactions would be exactly collinear with the immigrant share variable. As a result, we must balance the collinearity problem against the need to control for changes in the wage structure by allowing year effects to vary by education and experience in a limited way.

We attempt to capture the changes that occurred at both ends of the skill distribution by introducing a set of dummy variables that allow for some interactions between education, experience, and time. In particular, we introduce dummy variables indicating if the $(e, x, t)$ cell refers to a post-1980 observation of high school dropouts, a post-1980 observation of high school 
graduates or those with some college, or a post-1980 observation of college graduates. Moreover, for each education group we categorize individuals into very young, young, and older experience groups (1-10, 11-20, or 20 plus years of experience). This set of dummy variables is specifically designed to capture changes that occurred at the extremes of the wage distribution (in terms of both education and experience) before and after 1980.

It is worth emphasizing that the inclusion of this restricted set of education-experiencetime interactions does not impose any structure on why these changes may have occurred. As a result, the interactions capture not only the impact of the widening of the wage structure, but also the impact of the crack epidemic, as well as any kinds of changes in the composition of particular skill groups over time (e.g., the possibility that younger low-skill workers may be selected differently before and after 1980). In particular, one consequence of rising returns to skill may have been to raise the incentive for workers at all ability levels to obtain more education. If, within each skill group, more able workers are those more likely to complete additional schooling, then over time we would observe a decline in the average ability of workers in all education groups. Such an outcome would be more likely among the young, since their net benefit to completing more schooling is relatively high. Declining average ability within skill groups could result in all groups, and especially the young, exhibiting declining wages, declining employment rates, and rising incarceration rates, which are the same patterns that our theoretical model suggests would result from an immigration-induced labor supply shock. The included set of additional education-experience-time fixed effects allow for differential effects before and after 1980 among very young, young, and older workers, with low, average, or high levels of education. Hence we can partly control for changes in the average ability of individuals within experience-education group, focusing on those cases where the ability changes are likely to have been most pronounced.

The bottom panel of Table 2 reports the estimated coefficients from the specification with the restricted set of education-experience-time fixed effects. A number of results are worth noting. The wage effect of immigration is negative and significant-even after controlling for these changes in the wage structure at the extremes of the skill distribution. In fact, the adjustment coefficients are very similar for the two race groups: $-0.543(0.209)$ in the black regression and $-0.566(0.243)$ in the white regression. A 10-percent immigrant-induced increase in supply, therefore, reduces wages by around 4.0 percent. Second, immigration reduces the employment rate of both black and white workers. These effects are statistically significant, and 
the marginal impact on blacks is over twice as large as the marginal impact on whites. Finally, the use of the restricted set of education-experience-time interactions suggests that immigration had a significant impact on incarceration rates for both blacks and whites, with the marginal impact on blacks being seven times as large as the marginal impact on whites. A 10-percent immigrant induced increase in supply raises black incarceration rates by 0.8 percentage points and that of whites by 0.1 percentage points. ${ }^{28}$

The robustness of our results to major specification changes (such as the inclusion of the crack index or the restricted set of education-experience-time interactions) suggests that the national-level regressions may indeed be capturing the "true" effect of immigration on wages and the sectoral allocation of labor. However, because the impact of the crack epidemic (as well as concurrent changes in the judicial system) varied greatly across regions, we believe that it is important to determine if our estimated effects remain even when we analyze the evolution of wages and labor allocation within states.

\section{State Level Evidence}

We now examine the link between immigration and the evolution of wages, employment, and incarceration at the state level. This level of analysis has the advantage of letting us account more completely for the consequences of the crack epidemic. Crack first appeared in the early 1980s. It spread rapidly, reaching most of the country by the early 1990s (Grogger and Willis, 2000; Fryer et al. 2005). The criminal justice response followed shortly thereafter. Arrests for drug-related offenses rose substantially and many states stiffened penalties for drug-related offenses (Boggess and Bound, 1997; Charles and Luoh, 2005). Given the regional nature and timing of the consequences of the crack epidemic, much of the effect of the epidemic on the variables of interest may be absorbed by year-specific state fixed effects. ${ }^{29}$

\footnotetext{
28 We experimented with other specifications for the restricted set of education-experience-time interactions (e.g., allowing a dummy variable for each experience cohort for high school dropouts after 1980). This experimentation revealed that the evidence summarized in Table 2 adequately represent the results that can be obtained from a large family of alternative specifications - as long as the specifications include interactions that differentiate younger versus older workers separately for the two extreme education groups in the study.

${ }^{29}$ In particular, the state-level analysis helps us address the potential bias that may arise in the nationallevel study presented in the previous section if a relatively large immigrant influx happened to enter those states that have a relatively large black population and that also reacted to the crack epidemic with a crackdown of the drug trade and a substantial increase in incarceration rates.
} 
It is well known that the estimated wage impact of immigration at the state level will differ from that estimated at the national level. In response to an influx of immigrants in a state, native workers may choose to migrate to another state, possibly dampening the impact of immigration on local wages. To incorporate native migration between states into our theoretical framework, we extend the model presented in section III, extending theoretical results on the link between native wages, immigration and native migration reported in Borjas (2006).

The wage in the market sector for a particular skill group of race $i$ in state $r$ at time $t$ is given by:

$$
w_{i r t}=X_{f r}\left(1-\delta_{i}\right)\left(L_{f r t}\right)^{\eta_{f}},
$$

where $L_{r f t}$ gives the total number of persons working in the market sector in state $r$ at time $t$. Note that the market sector labor demand shifter $\left(X_{f r}\right)$ is allowed to vary across states, but the market sector wage elasticity $\left(\eta_{f}\right)$ is assumed to be constant across states. Equation (11) gives the marginal productivity condition for a particular skill group in a particular regional labor market. For simplicity, we omit the subscript indicating the skill group $(s)$ throughout some of the discussion.

Suppose labor market $r$ is initially in a pre-immigration long-run equilibrium. The immigrant influx begins at time $t=0$. In particular, $M_{r}$ immigrants arrive in state $r$ in each period. As long as immigration is not properly "balanced" across states, immigration creates regional wage differences for a particular skill group. These differences motivate natives to migrate to higher-wage regions. Because such migration is costly, the native labor supply response to supply shocks (or to local labor demand shocks) is not instantaneous. As in Borjas (2006), suppose that the migration rate of natives of racial group $i$ residing in state $r$ between periods $t-1$ and $t$ is:

$$
v_{r t}=\sigma\left(\ln w_{r, t-1}-\ln \bar{w}_{t-1}\right)
$$

where $v_{r t}=\Delta N_{r t} /\left(N_{b f r}^{*}+N_{w f r}^{*}\right)$ is the inflow of natives (of all races) as a share of native employment in the market sector in the pre-immigration equilibrium; $\sigma>0$ is the supply elasticity; and $\ln \bar{w}_{t-1}$ is the average log wage in the national economy at time $t-1$. Part 2 of the 
Mathematical Appendix shows that the solution to this model implies that the market wage (for a particular skill group $s$ ) of the native workforce in state $j$ is given by:

$$
\ln w_{i r s t}=\ln w_{i r s}^{*}+\eta_{f} \rho\left(1+\sigma \eta_{f} \rho\right) m_{r s t}-\sigma \eta_{f}^{2} \rho^{2} m_{s t}
$$

where $w_{i r s}^{*}$ is the wage of workers of race $i$ in state $j$ with skills $s$ in the pre-immigration equilibrium; $m_{r s t}$ is the immigrant share in state $j$ 's workforce as of time $t$; and $m_{s t}$ is the immigrant share in the national workforce at that time. These shares are defined as a fraction of the initial native workforce in the pre-immigration equilibrium.

Equation (13a) gives the state-level counterpart to the national-level wage in equation (6a). It is important to emphasize that the state-level wage depends both on immigration into state $r\left(m_{r s t}\right)$ as well as on the national level of immigration $\left(m_{s t}\right)$. The model predicts that both of these variables will have a negative impact on the market wage.

The economic intuition for the inclusion of both state-level and national-level immigrant shares in the state-level wage regression is obvious: The influx of immigrants into a particular state does not capture the entire impact of immigration on that particular regional labor market. Immigrants also enter other states, and the native migration response internalizes the impact of this out-of-state immigration into state $r$. In short, any native response (whether in terms of labor flows or capital flows) inevitably implies that local supply shocks do not adequately measure the size of the immigrant influx and hence do not capture the entire wage impact of immigration.

Put differently, a regression of local-level wages on the local-level measure of the immigrant supply shock is not correctly specified. Including only the local immigrant share in the regression, which is the convention in most of the existing literature, produces estimates of the wage effect of immigration that are too small. Indeed, equation (13a) shows that the sum of the coefficients on $m_{r s t}$ and $m_{s t}$ equals $\eta_{f} \rho$, the reduced-form wage elasticity that we introduced in the national wage equation (6a). The coefficient on the state-level immigration share by itself could easily (and, as we show, does) provide a substantially downward-biased estimate of the reduced-form effect of immigration on wages.

Natives in each state have the option of working in the market sector, participating in crime, or taking leisure, where crime and leisure demand shifters may vary across states but the 
wage elasticities in these activities $\left(\eta_{i c}, \eta_{i h}\right)$ do not. We assume that wages in the various activities are equalized across sectors for each region-race group combination.

Based on equation (13a), we can then obtain the equations determining the sectoral employment levels for each race group in state $j$ :

$$
\begin{aligned}
& \ln N_{i c r s t}=\ln N_{i c r s}^{*}+\frac{\eta_{f} \rho\left(1+\sigma \eta_{f} \rho\right)}{\eta_{i c}} m_{r s t}-\frac{\sigma \eta_{f}^{2} \rho^{2}}{\eta_{i c}} m_{s t}, \\
& \ln N_{i h r s t}=\ln N_{i h r s}^{*}+\frac{\eta_{f} \rho\left(1+\sigma \eta_{f} \rho\right)}{\eta_{i h}} m_{r s t}-\frac{\sigma \eta_{f}^{2} \rho^{2}}{\eta_{i h}} m_{s t}, \\
& \ln N_{i f r s t}=\ln N_{i f f s}^{*}-\frac{1}{\theta_{i f r}}\left(\frac{\theta_{i c r s}}{\eta_{i c}}+\frac{\theta_{i h r s}}{\eta_{i h}}\right)\left[\eta_{f} \rho\left(1+\sigma \eta_{f} \rho\right) m_{r s t}-\sigma \eta_{f}^{2} \rho^{2} m_{s t}\right] .
\end{aligned}
$$

As in our national labor market model, higher levels of immigration are associated with higher native employment in crime, greater native leisure, and lower native formal employment. The marginal impact of immigration on black market employment and crime would be larger than that on whites as long as the crime and leisure demand elasticities are larger for blacks. It is again worth emphasizing that both the state-level and national-level immigration shares affect the sectoral distribution of employment in state $r$, with the sum of the respective coefficients equaling the national level coefficients in (6b)-(6d).

The state-level results presented below are based on a regression model where $y_{\text {rext }}$ denotes the mean value of a particular labor market outcome for men who live in state $r$, have $e$ years of education, $x$ years of labor market experience, and are observed at time $t$. There are now a potential 8,160 cells in the analysis. ${ }^{30}$ We calculated $y_{\text {rext }}$ using the sample of native-born men who are either black or white. Consider the following regression model:

$$
y_{\text {rext }}=\theta_{R} p_{\text {rext }}+\theta_{N} p_{\text {ext }}+R+E+X+T+(R \times T)+(E \times T)+(X \times T)+(R \times E \times X)+\varepsilon_{\text {rext }}
$$

30 The actual number of observations differs from the potential maximum for two main reasons. First, there are many cells where there are no blacks in the sample. Second, the measured incarceration rate in many cells is zero. The use of the log odds ratio to estimate the employment and incarceration rate regressions implies that zeromean cells are excluded from the analysis. To evaluate the sensitivity of our results, we estimated the relevant models using a linear probability estimator and tried both including and excluding the zero-mean cells. The results suggest that the inclusion of the zero-mean cells lead to marginal impacts that are at least as large as those reported in the paper. 
where $R$ is a vector of fixed effects indicating the state of residence; $E$ is a vector of fixed effects indicating the education group; $X$ is a vector of fixed effects indicating experience group; and $T$ is a vector of fixed effects indicating the year in which the data are observed. ${ }^{31}$ As with the national-level regression specified earlier, the various vectors of fixed effects absorb any regionspecific, skill-specific, and time-specific factors that affect the evolution of the dependent variable in a particular labor market. The standard errors reported in this section are clustered at the state-education-experience level. ${ }^{32}$ As in our national level analysis, the employment and incarceration rate regressions use the grouped-logit version of equation (14).

Table 3 reports the relevant regression coefficients from the state-level wage equations. Panel A presents least squares estimates. The first row shows the immigration coefficient from a model that excludes the national-level immigration share. This is the type of model that is typically estimated in the literature. The coefficient for blacks is -0.266 , which is less than half the size of the national-level coefficient of -0.561 reported in Table 2.

Our theoretical model, however, showed that the true reduced-form wage elasticity from a state-level regression is given by the sum of the coefficients of the state- and national-level immigration shares. Estimates from this generalized state-level model are reported in row 2 of panel A. Adding the national-level immigration share changes the state-level coefficient only slightly. Moreover, the national-level coefficient is itself numerically sizable and statistically significant. Our theoretical model implies that this constitutes a rejection of the hypothesis that regional labor markets are isolated and are only affected by local supply shocks.

More importantly, the "true" reduced-form wage effect, as estimated by the sum of the coefficients of the state- and national-level immigration shares, is large. The sum of the coefficients for blacks is $-0.697(0.155)$. This estimate is larger than the coefficient of -0.561 from the national-level regression reported in Table 2, although the standard errors are sufficiently large that one cannot reject the hypothesis that the two reduced-form wage effects are equal. For whites, the corresponding sum is -0.790 (and, again, the hypothesis that the

\footnotetext{
31 In contrast to the national level regressions presented in the previous section, we do not allow the full set of interactions that would be theoretically possible. In particular, we are omitting separate three-way vectors of interactions between education-region-time, experience-region-time, and education-experience-time.

32 Our choice of clustering variable is very conservative. Clustering at the state level would often generate lower standard errors for the coefficients reported in Tables 2 and 3 below.
} 
national wage effect equals the state-level wage effect cannot be rejected). Further, these coefficients are consistent with the theoretical implication that immigration should affect the wages of blacks and whites equally as long as the two groups (within narrowly defined skill categories) are perfect substitutes in the market sector.

Panel B of the table replicates the analysis using the immigrant share in the population at the state level and national level as instruments. The IV coefficients are very similar to the corresponding least squares estimates.

The IV estimates reported in Panel $\mathrm{C}$ of the table are based on models that include interactions between the region-skill fixed effects and the state-level crack index. In particular, we estimate the regression model:

$$
\begin{aligned}
y_{\text {rext }} & =\theta_{R} p_{\text {rext }}+\theta_{N} p_{\text {ext }}+R+E+X+T+(R \times T)+(E \times T)+(X \times T) \\
& +(R \times E \times X)+(R \times E \times X) C_{r t}+\varepsilon_{r s t},
\end{aligned}
$$

where $C_{r t}$ is the Fryer et al (2005) crack index for state $r$ at time $t .{ }^{33}$ In these models, the crackskill group interactions allow the effects of skill to vary over time as a function of the extent of crack activity within the state.

Adding the state-skill-crack interactions to the models has little effect on the state-level coefficient, but reduces the national-level coefficients (compare the estimates in Panels B and C of the table). However, a reduction is not found when we use the restricted crack index, reported in panel D (where we set the state-level crack index at zero for all cells that contain workers who are either high school graduates or have more than 20 years of experience).

Finally, Panel E of the table illustrates the wage effects of immigration when we include the restricted set of education-experience-year interactions to capture specifically what happened to the wage structure at the bottom and top ends of the skill distribution in the 1980s and 1990s. ${ }^{34}$ The estimated coefficients clearly indicate that both the state-level and national-level immigrant

33 These regressions make use of Fryer, et al's state-specific crack index, which varies by state and year. We use the average value of the index for the two calendar years preceding the Census.

34 As in the previous section, these interactions include dummy variables indicating whether a cell refers to a post-1980 observation of high school dropouts, a post-1980 observation of high school graduates or those with some college, or a post-1980 observation of college graduates, where for each education group we categorize individuals into very young, young, and older experience groups (1-10, 11-20, or 20 plus years of experience). 
shares have significant and numerically sizable impacts on the wage of both black and white workers.

Table 4 reports the regression coefficients for the state-level analysis using the other dependent variables in our study. For convenience, all of the models include both the state- and national-level immigration shares. We also report the sum of the two coefficients.

The top panel presents the basic OLS estimates. Immigration reduces employment rates and raises incarceration rates for both blacks and whites, although the marginal effects are numerically bigger for blacks. In nearly all of these models, the national-level immigration share is significant, which is consistent with the notion that local labor markets are linked and that the impact of immigration into one region spills over into other regions. It is worth noting that, for each outcome, the sum of the state- and national-level immigration coefficients is roughly similar to the national-level coefficient reported in Table 2.

The remaining panels of the table report IV estimates from models that include either the state-level crack index or a limited set of interactions between education, experience, and year fixed effects. For the most part, these estimates are similar to the least squares estimates in the top panel. The coefficient of the state-level immigration variable tends to be numerically smaller than that of the national-level immigration variable. In fact, the state-level immigration coefficient is often insignificant in the incarceration regressions that use the concurrent immigration measure, but are slightly more significant in the regressions that use the lagged immigration variable. Note, however, that the sum of coefficients (which measures the true impact of immigration) is statistically significant in almost every specification of the employment and incarceration regressions reported in Table 4. Equally important, the marginal impact implied by the sum of the coefficients is roughly similar to that estimated in the nationallevel models in the previous section. For example, using the marginal effects reported in Panel E of Table 4, a 10-percent immigrant-induced increase in supply reduces the employment rate of blacks by 2.3 percentage points and that of whites by 1.7 percentage points. The comparable statistics implied by Panel E of the national-level results reported in Panel E of Table 2 are 3.5 and 1.6 percentage points, respectively. Similarly, the state-level regressions imply that a 10percent immigrant-induced increase in supply raises the incarceration rate of blacks by 0.8 percentage points and that of whites by 0.1 percentage points, and these are exactly the same marginal impacts implied by the national level analysis. 


\section{Measurement Error}

There exists an alternative, non-economic explanation for the significance of the national immigration share in the state-level regression model. Aydemir and Borjas (2006) argue that sampling error in estimates of state-level immigrant shares may result in biased estimates of the relation between state-level wages and immigration. One might then speculate that the inclusion of the national-level share in equation (15) might compensate for some of the state-level measurement error in regressions that include both measures.

To address this issue, we examine the properties of our estimates under the assumption that the true model involves only the state-level shares (i.e., there is no native migration response to immigration), but the estimated model includes both the state and national immigration shares as regressors. Abstracting from the other regressors in the model, we adopt a simplified notation and assume the true model to be:

$$
y_{R}=\theta \pi_{R}+\varepsilon_{R}
$$

where $y_{R}$ denotes the state-level dependent variable, $\pi_{R}$ denotes the true state-level immigrant share, and $\varepsilon_{R}$ denotes the disturbance term. In this notation, $y_{R}, \pi_{R}$, and $\varepsilon_{R}$ are vectors. The unit of analysis is an observation on wage-immigration outcomes in a particular labor market (defined by skills and time). The estimated model is given by:

$$
y_{R}=\theta_{R} p_{R}+\theta_{N} p_{N}+\varepsilon,
$$

where $p_{R}$ is the measured state-level immigrant share and $p_{N}$ is the measured national-level share. Measurement error takes the form:

$$
\begin{aligned}
& p_{R}=\pi_{R}+v_{1} \\
& p_{N}=\pi_{R}+v_{2}
\end{aligned}
$$

We assume that $\varepsilon_{\mathrm{R}}, v_{1}$, and $v_{2}$ are uncorrelated with each other, and that $\varepsilon_{R}$ and $v_{1}$ are uncorrelated with $p_{R}$. However, since $p_{N}$ represents the mean of $p_{R}$ across states, $v_{2}$ represents a 
deviation from the mean of $p_{R}$, which implies that $v_{2}$ is uncorrelated with $p_{N}$ but correlated with $p_{R}$. Part 3 of the Mathematical Appendix demonstrates that under these assumptions:

$$
\begin{aligned}
& \operatorname{plim} \hat{\theta}_{R}=\theta \frac{\operatorname{var}\left(v_{2}\right)}{\operatorname{var}\left(v_{1}\right)+\operatorname{var}\left(v_{2}\right)}, \\
& \operatorname{plim} \hat{\theta}_{N}=\theta \frac{\operatorname{var}\left(v_{1}\right)}{\operatorname{var}\left(v_{1}\right)+\operatorname{var}\left(v_{2}\right)} .
\end{aligned}
$$

Note that even when the true regression model is given by equation (16), the national-level immigrant share will influence state-level labor market outcomes if there is measurement error in the state-level shares - and that the impact of the national-level share will be larger the greater the measurement error in the state-level share. Moreover, equations (19a) and (19b) imply that:

$$
\theta=\operatorname{plim} \hat{\theta}_{R}+\operatorname{plim} \hat{\theta}_{N}
$$

In other words, in the presence of measurement error the true impact of immigration at the statelevel is given by the sum of the state-level and national-level coefficients.

The bottom panel of Table 3 indicates that the state-level black wage regression yields a state-level coefficient equal to -0.238 and a national-level coefficient of -0.407 . The respective coefficients for whites are -0.129 and -0.524 . Note that the national-level coefficient is numerically larger than the state-level coefficient for both race groups, suggesting that, if equation (16) is the true model, there must be a great deal of measurement error in the state-level immigrant share. Suppose the only source of measurement error in the state-level immigrant share is sampling error. Because the immigrant share is a proportion, one can work out the exact nature of the sampling error. Aydemir and Borjas (2006) show that the sampling error in $p_{R}$ is given by:

$$
\operatorname{var}\left(v_{1}\right)=(1-f) E\left(\frac{\pi_{R}\left(1-\pi_{R}\right)}{n_{R}}\right) \approx(1-f) \frac{\bar{p}(1-\bar{p})}{\bar{n}}
$$


where $f$ is the sampling fraction (i.e., the fraction of the population included in the sample), $\bar{p}$ is the average immigrant share, and $\bar{n}$ is the average cell size used in the calculation. In our analysis, the sampling fraction is 0.05 (as most of the data comes from a 5 percent random sample), the average immigrant share is 0.1 , and the average cell size in a particular state-skillyear observation is approximately 1,200 . This implies that $\operatorname{var}\left(v_{1}\right)$ is a small number, less than 0.0001. On the other hand, $\operatorname{var}\left(v_{2}\right)$, which measures the "between variance" in the immigrant share across states, is quite large, about 0.0049. The evidence reported in Table 3, therefore, is inconsistent with the conjecture that equation (16) is the true model determining immigrant wages at the state level, and that measurement error is the only reason for the national-level immigrant share to matter in determining state-level wages. Instead, it seems that a behavioral response by native labor (or capital) is responsible for diffusing the impact of immigration across states.

\section{Accounting for the Trends in Employment and Incarceration Rates}

We now use the regression coefficients estimated in the last two sections - both from the national-level and state-level models - to determine the extent to which the immigration-induced shift in supply accounts for the decline in black wages and employment and the increase in black incarceration. In particular, we use the coefficients estimated in the previous sections to simulate the impact of the immigrant influx that entered the United States between 1980 and 2000.

Suppose the estimated regression coefficient for a particular outcome $y$ (and for a particular race group) is $\hat{\theta}$, where $\hat{\theta}$ represents either the immigration coefficient from the national-level model or the sum of the state- and national-level immigration coefficients from the state-level model (i.e., $\hat{\theta}=\hat{\theta}_{R}+\hat{\theta}_{N}$ ). Equation (9) then implies that the reduced-form impact of an immigrant influx that increases the supply of education group $e$ by $m_{e}$ percent can be approximated by:

$$
\Delta y_{e}=\hat{\theta}(1-\bar{p})^{2} m_{e}
$$

where we evaluate the derivative in (9) at the mean value of the immigrant share observed in 2000. Because we are interested in simulating the impact of the cohort of immigrants that entered the United States between 1980 and 2000, we define the supply shock as: 


$$
m_{e}=\frac{M_{e, 2000}-M_{e, 1980}}{0.5\left(N_{e, 1980}+N_{e, 2000}\right)+M_{e, 1980}},
$$

so that the baseline population used to calculate the percent increase in labor supply averages out the (changing) size of the native workforce during the 1980-2000 period and treats the preexisting immigrant population as part of the "native" stock.

Table 5 summarizes the results of the simulation. Column 1 of the table reports the actual change in the log weekly wage, employment, and incarceration rates experienced by black and white men during the 1980-2000 period. ${ }^{35}$ The changes in wages, employment and incarceration rates are quite large for black men, and particularly for low-skill black men. Between 1980 and 2000, for example, the real wage of black high school dropouts (a group that made up 25 percent of the black male population in 1990), wages fell by 14 percent, the employment rate fell by 17.9 percentage points, and the incarceration rate rose by 19.9 percentage points.

Columns 2 and 3 of the table summarize the results of the simulation when we use the adjustment coefficients estimated at the national level and reported in Panel E of Table 2. Equation (22) predicts that, other things equal, the 1980-2000 immigrant influx reduced the wage of black high school dropouts by 8.3 percent, reduced the employment rate by 7.4 percentage points, and increased the incarceration rate by 1.7 percentage points. These predicted impacts are sizable and account for 60 percent of the observed reduction in wages, 41 percent of the observed decline in employment, and 8 percent of the rise in incarceration rates. In other words, immigration contributed a numerically significant amount to the trends among low-skill blacks, but much of the decline in wages and employment and the rise in incarceration would have been observed even in the absence of the 1980-2000 immigrant influx.

The simulation provides roughly similar results for black high school graduates (a group that formed 43 percent of the black male population in 1990). Immigration reduced black wages by 3.2 percent (as compared to an actual reduction of 8.5 percent) and reduced the employment rate by 2.8 percentage points (as compared to an actual decline of 9.8 percentage points). Similarly, immigration increased the black incarceration rate by 0.6 percentage points (as compared to an actual rise of 8.4 percentage points). The 1980-2000 immigrant influx, therefore,

\footnotetext{
35 The reported statistics for "all persons" in Table 5 are calculated using a fixed-weight weighted average of the changes observed for the various education groups. The fixed weights equal the average of the 1980 and 2000 race-specific education distributions.
} 
generally "explains" about 40 to 60 percent of the decline in wages, 30 to 40 percent of the decline in employment, and about 10 percent of the rise in incarceration rates among blacks with a high school education or less.

Table 5 also shows that our approach cannot explain the observed changes in wages or employment for high-skill blacks. In the sample of black college graduates, for example, immigration is predicted to reduce wages by 4.4 percent and employment rates by 3.9 percent, whereas they rose by 12.7 percent and 0.6 percent, respectively. The key underlying assumption of the simulation - that "other things are equal" in the 1980-2000 period - clearly misses an important part of what was driving employment opportunities for high-skilled workers at that time. The wage structure was changing dramatically during this period, particularly affecting the opportunities of workers at the top of the wage distribution. The simulation reported in Table 5 does not account for these shifts.

A second caveat on the interpretation of the predicted changes in employment and incarceration rates for college graduates is that the regressions reported above impose the restriction that the labor demand elasticities described in equations (2)-(4) are invariant to skill. We might imagine that the elasticity of labor demand in crime, in particular, varies by education level, with elasticities being larger for the less-educated. If the demand for highly educated labor in crime is in fact relatively inelastic, we would overstate the impact of immigration on their employment and incarceration rates.

Finally, it is important to stress that the "all other things equal" assumption ignores the capital adjustments induced by the immigrant supply shock. Over time, these capital adjustments attenuate the wage effects of immigration. If the aggregate production function had constant returns to scale, for example, the capital adjustments would eventually raise the average wage in the labor market back to its pre-immigration equilibrium level. Even in the long run, however, immigration may still have significant distributional effects. In a CES framework, the long-run relative wage effects of immigration are obtained by simply differencing the effects across the different education groups reported in Table 5 (Borjas and Katz, 2007). For example, even after all capital adjustments take place, the 1980-2000 immigrant influx lowered the wage of black high school dropouts relative to that of college graduates by 3.9 percent (or $-0.083-(-0.044)$ ). These relative wage effects suggest that there would also be sizable relative employment effects and relative incarceration effects. 
The bottom two panels of Table 5 replicate the analysis for white employment and incarceration rates. The 1980-2000 immigrant influx reduced the wages of white high school dropouts by about 8.6 percent, or about 40 percent of the observed change. The influx also lowered the employment rate by 3.2 percentage points, or about 30 percent of the decline actually observed in the white sample. Immigration also explains a smaller portion (about 5 percent) of the increase in incarceration rates observed among low-skill white men.

The comparison of the simulation results for black and white men suggests that the 19802000 immigrant influx had roughly similar impacts on wages by race, but had a bigger impact on both employment rates and incarceration rates for blacks. The predicted decline in employment rates is more than twice as large for blacks as for whites (3.2 percentage points for blacks as compared to 1.4 percentage points for whites). Similarly, the predicted increase in incarceration rates is seven times as large for blacks ( 0.7 percentage points for blacks as compared to 0.1 percentage points for whites). In short, immigration contributed to the widening of the racial gap in employment and incarceration rates over the period.

Columns 4 and 5 of Table 5 replicate the entire exercise using the sum of the state- and national-level immigration coefficients estimated in the state-level regressions and reported in Panel E of Tables 3 and 4. These estimates are very similar to those in columns (2) and (3). The reason is that the estimated effect of immigration is similar in the two sets of models, provided we use the sum of the state- and national-level coefficients from the state-level models to estimate the effect of immigration.

Before concluding, it is useful to compare our findings to related results in the labor supply and crime literatures. Juhn, Murphy, and Topel (1991), for instance, estimate the elasticity of labor supply with respect to wages for low-skill workers along both the extensive and intensive margins. They report an estimate of 0.4 . We can compare their estimate with implicit estimates from our analysis of the responsiveness of employment and wages to immigration. 36

Table 5 indicates that the wage of high school dropouts fell by about 8 percent in response to the 1980-2000 immigrant influx, while the wage of high school graduates fell by

\footnotetext{
${ }^{36}$ Note that the reduced-form estimate of the impact of immigration on employment (or incarceration) rates can be combined with the reduced-form estimate of the wage impact of immigration to calculate the IV estimate of the relation between employment rates and wages, where the immigrant share is the instrument. The IV estimate of the employment elasticity is given by the ratio of the coefficients of the immigrant share variable from the employment and wage regressions.
} 
about 3 percent. These estimates, combined with the employment impacts reported in the table and baseline employment rates from 1980, imply that the elasticity of employment with respect to wages is roughly 0.9 for blacks, and about 0.4 for whites. ${ }^{37} \mathrm{~A}$ weighted average that accounts for each group's representation within education cells yields overall employment elasticity estimates of 0.47 for high school dropouts and 0.48 for high school graduates. ${ }^{38}$ Thus our estimates are roughly similar to those reported by Juhn, Murphy and Topel.

We are not aware of any previous estimates of the effect of the market wage on incarceration, although a small literature estimates the relation between crime rates and the wage. Using data from the NLSY, Grogger (1998) finds that the derivative of crime participation with respect to the market log wage is -0.25 . Table 5 shows that the $1980-2000$ immigrant influx increased incarceration rates by 1.7 percentage points for black high school dropouts and by 0.6 percentage points for black high school graduates. Combining these results with the wage effects implies that the derivative of the incarceration rate with respect to log wages is about -0.20 for both black low-skill groups. For whites, the corresponding derivative is -0.02 for high school dropouts and -0.03 for high school graduates. Weighted averages yield derivatives of -0.06 for all high school dropouts and for all high school graduates.

How do these numbers compare with Grogger's (1998) estimate? Suppose incarceration is proportional to crime participation, with the factor of proportionality being the conditional probability that criminals end up in jail. The derivative of incarceration with respect to the wage is then proportional to the derivative of crime participation with respect to the wage. Therefore, our evidence is consistent with the earlier estimate if roughly one-fifth to one-third of criminals are incarcerated. By at least one metric, these conditional incarceration probabilities seem reasonable: Since over 20 percent of black high school dropouts were incarcerated in 2000, we know that far more than 20 percent of black dropout criminals were incarcerated. ${ }^{39}$

37 Among blacks, employment rates in 1980 were 0.59 for high school dropouts and 0.74 for high school graduates. Among whites, the respective figures were 0.74 and 0.87 . graduates.

38 In 1980, blacks made up 18 percent of male high school dropouts and 10 percent of male high school

39 Gould, Weinberg, and Mustard (2002) and Machin and Meghir (2004) use aggregate data to estimate the elasticity of crime with respect to wages, and both studies report estimates centered roughly around -1.0. However it is very difficult to compare our estimates to theirs because of the minuscule base incarceration rate in our sample. 


\section{Summary}

It is well known that black employment rates declined substantially over the past few decades, and that this decline was accompanied by a rapid rise in the black incarceration rate. This paper examines a simple yet potentially controversial question: has the resurgence of largescale immigration in the United States contributed to these trends?

We use data drawn from the microdata files of the 1960-2000 U.S. Censuses to examine the trends in black wages, employment, and incarceration. Our empirical analysis examines the link between immigration and the evolution of these variables over the four-decade period - after adjusting for other factors that could account for shifts in the wage structure as well as shifts in opportunities in the "formal" labor market and in the crime sector. We find a numerically sizable and statistically significant negative correlation between immigration and the wages of black men; a sizable and significant negative correlation between immigration and the employment rate of black men; and a sizable and significant positive correlation between immigration and the incarceration rate of black men. It is important to emphasize that we find similar correlations for white men, but the magnitude of these correlations differ in important ways between the two groups. Although the wage effect of immigration is similar for black and white men, the negative employment effect and the positive incarceration effect are larger for blacks.

Our empirical analysis uses both national- and state-level data to document the impact of immigration on black wages and employment. Although the literature uniformly finds that estimates of the wage effects of immigration are much smaller when one uses geographically smaller units (such as a state), our theoretical approach provides a simple and intuitive method for synthesizing the national- and state-level studies in the literature. The state-level regression of the state wage on the immigration supply shift in that state is misspecified as long as natives, either through labor or capital flows, diffuse the impact of immigration into one particular state to other states. By including measures of both state-level and national-level supply shocks, one can estimate the "true" reduced-form effects of immigration, and these reduced-form effects are similar to those revealed by national labor market studies.

The economic adjustments unleashed by the large 1980-2000 immigrant influx, a labor supply shock that increased the number of workers in the United States by nearly 10 percent and the number of high school dropouts by over 20 percent, reduced the employment rate of low-skill black men by about 8 percentage points. Immigration, therefore, accounts for about 40 percent of the 17.9 percentage point decline in black employment rates. Similarly, the changes in economic 
opportunities caused by the 1980-2000 immigrant influx raised the incarceration rate of black high school dropouts by 1.7 percentage points, accounting for almost 10 percent of the 19.9 percentage point increase observed during that period. Put differently, although immigration played a numerically important role, much of the decline in employment and increase in incarceration observed in the low-skill black population would have taken place even if the immigrant influx had been far smaller. 


\section{DATA APPENDIX}

The data are drawn from the 1960, 1970, 1980, 1990, and 2000 Integrated Public Use Microdata Samples (IPUMS) of the U.S. Census. In the 1960 and 1970 Censuses, the data extract forms a 1 percent sample of the population. In the 1980, 1990, and 2000, the data extracts form a 5 percent sample. The analysis is restricted to men aged 18-64. A person is classified as an immigrant if he was born abroad and is either a non-citizen or a naturalized citizen; all other persons are classified as natives. We use the information contained in the census race variable to classify persons as "black" (IPUMS variable raced $=200$ ) or "white" (raced $=100$ or 110). Sampling weights are used in all calculations.

Definition of education and experience: We use the IPUMS variables educrec to classify workers into four education groups: high school dropouts (educrec $<=6$ ), high school graduates $($ educrec $=7)$, persons with some college $($ educrec $=8)$, college graduates $($ educrec $=9)$. We assume that high school dropouts enter the labor market at age 17, high school graduates at age 19 , persons with some college at age 21 , and college graduates at age 23 , and define work experience as the worker's age at the time of the survey minus the assumed age of entry into the labor market. We restrict the analysis to persons who have between 1 and 40 years of experience. Workers are classified into one of 8 experience groups, defined in five-year intervals.

Counts of persons in education-experience groups: The workforce counts are calculated in the sample of men who worked at some point in the calendar year prior to the census, are not enrolled in school, and are not in the military during the survey week. The population counts are calculated in the sample of men who are not enrolled in school and are not in the military during the survey week.

Weekly earnings: We use the sample of men who do not reside in group quarters, report positive weeks worked, are not in the military in the reference week, and report positive earnings. Our measure of earnings is the sum of the IPUMS variables incwage and incbusfm in 1960, the sum of incearn, incbus, and incfarm in 1970 and 1980, and is defined by incearn in 1990-2000. In the 1960, 1970, and 1980 Censuses, the top coded annual salary is multiplied by 1.5. All earnings are deflated to 1990 dollars. In the 1960 and 1970 Censuses, weeks worked in the calendar year prior to the survey are reported as a categorical variable. We imputed weeks worked for each worker as follows: 6.5 weeks for 13 weeks or less, 20 for 14-26 weeks, 33 for 27-39 weeks, 43.5 for 40-47 weeks, 48.5 for 48-49 weeks, and 51 for 50-52 weeks. The average log weekly earnings for a particular education-experience cell is defined as the mean of $\log$ weekly earnings over all workers in the relevant population.

Employment and incarceration rates: These variables are calculated in the sample of men who are not enrolled in school. The employment rate is the sample average of the ratio of weeks worked during the calendar year prior to the Census, including zeros, to 52. In the 1960, 1970, and 1980 Censuses, a person is institutionalized if the group quarter variable gqtype takes on a value that is between 2 and 4 (indicating that the person is in a correctional institution, mental institution, or other institution at the time of the Census). In 1990 and 2000, the person is institutionalized if gqtype takes on a value of 1 (indicating the person is in an institution). The 1990 and 2000 Censuses do not provide detailed information on the type of institution where an institutionalized person resides. 


\section{MATHEMATICAL APPENDIX}

\section{Derivation of equations (6a)-(6d)}

Equate equations (2) and (3) in the text. This yields:

$$
N_{i c s}=g\left(\frac{X_{f s}}{X_{i c s}}, L_{f s}\right)=\left(\frac{X_{f s}}{X_{i c s}}\right)^{1 / \eta_{i c}}\left(L_{f s}\right)^{\eta_{f} / \eta_{i c}} .
$$

We linearize equation (A1) using a multivariate first-order Taylor series approximation. The linearization is conducted at the arbitrary point:

$$
\bar{N}_{f}=\frac{1}{S} \sum_{s=1}^{S} N_{f s}^{*}, \quad \overline{X_{f} / X_{i c}}=\frac{1}{S} \sum_{s=1}^{S}\left(X_{f s}^{*} / X_{i c s}^{*}\right),
$$

where the asterisks indicate the values of the variables in the pre-immigration equilibrium and $S$ gives the number of skill groups. Recall that $L_{f}$ gives the sum of natives $\left(N_{f}\right)$ and immigrants $(M)$ in the market sector. In the pre-immigration equilibrium, it must be the case that $L_{f}=N_{f}$. The first-order approximation of (A1) can then be written as:

$$
\begin{aligned}
& N_{i c s}=g\left(\overline{X_{f} / X_{i c}}, \bar{N}_{f}\right)+g_{1}\left(\overline{X_{f} / X_{i c}}, \bar{N}_{f}\right)\left(X_{f s} / X_{i c s}-\overline{X_{f} / X_{i c}}\right) \\
& +g_{2}\left(\overline{X_{f} / X_{i c}}, \bar{N}_{f}\right)\left(L_{f s}-\bar{N}_{f s}\right)
\end{aligned}
$$

where $g_{1}=\partial g / \partial\left(X_{f s} / X_{i c s}\right)$ and $g_{2}=\partial g / \partial L_{f s}$. Given (A1) these derivatives are:

$$
\begin{aligned}
& g_{1}=\frac{N_{i c s}}{\eta_{i c}}\left(\frac{X_{f s}}{X_{i c s}}\right)^{-1}, \\
& g_{2}=\frac{\eta_{f}}{\eta_{i c}} \frac{N_{i c s}}{L_{f s}} .
\end{aligned}
$$

If we evaluate these derivatives at the points defined in (A2), the first-order approximation is:

$$
N_{i c s}=\alpha_{i c s}+\beta_{i c} L_{f s},
$$

where:

$$
\begin{aligned}
\alpha_{i c s}= & g\left(\overline{X_{f} / X_{i c}}, \bar{N}_{f}\right)-g_{1}\left(\overline{X_{f} / X_{i c}}, \bar{N}_{f},\right) \overline{X_{f} / X_{i c}}+g_{1}\left(\overline{X_{f} / X_{i c}}, \bar{N}_{f}\right)\left(X_{f s} / X_{i c s}\right) \\
& -g_{2}\left(\overline{X_{f} / X_{i c}}, \bar{N}_{f}\right) \bar{N}_{f} \\
\beta_{i c}= & g_{2}\left(\overline{X_{f} / X_{i c}}, \bar{N}_{f}\right) .
\end{aligned}
$$

Note that the intercept in (A5) is a function of the skill level $s$, but the slope $\beta_{i c}$ is not. By using a similar method, we can derive the analogous linear approximation for $N_{i h s}$ : 


$$
N_{i h s}=\alpha_{i h s}+\beta_{i h} L_{f s},
$$

In the post-immigration equilibrium, the total number of persons participating in the market sector can be written as:

$$
L_{f s}=\left(\tilde{N}_{b s}+\tilde{N}_{w s}+M_{s}\right)-N_{b c s}-N_{w c s}-N_{b h s}-N_{w h s},
$$

where $\tilde{N}_{i s}$ gives the number of native persons of race $i$ and skill $s$ in the population. By substituting equations (A5) and (A7) into (A8), and solving for $L_{f s}$ we obtain:

$$
L_{f s}=\alpha_{s}+\rho\left(\tilde{N}_{b s}+\tilde{N}_{w s}+M_{s}\right)
$$

where $\rho$ is a constant that is not race-specific and that does not depend on skills. In fact, it follows from the definition of $g_{2}$ that:

$$
0<\rho=\left[\frac{\bar{N}_{f}}{\bar{N}_{f}+\frac{\eta_{f}}{\eta_{b c}} \bar{N}_{b c}+\frac{\eta_{f}}{\eta_{w c}} \bar{N}_{w c}+\frac{\eta_{f}}{\eta_{b h}} \bar{N}_{b h}+\frac{\eta_{f}}{\eta_{w h}} \bar{N}_{w h}}\right]<1 .
$$

where $\bar{N}_{i c}=g\left(\overline{X_{f} / X_{i c}}, \bar{N}_{f}\right)$ and $\bar{N}_{i h}$ is defined analogously. The intercept $\alpha_{s}$ in equation (A8) does depend on skills and is defined by:

$$
\alpha_{s}=-\left(\alpha_{b c s}+\alpha_{w c s}+\alpha_{b h s}+\alpha_{w h s}\right) \rho \text {. }
$$

It follows from equation (A9) that $N_{f s}^{*}=\alpha_{s}+\rho\left(\tilde{N}_{b s}+\tilde{N}_{w s}\right)$ in the pre-immigration equilibrium. Substituting this into equation (2) in the text implies that the pre-immigration equilibrium wage is:

$$
\ln w_{i s}^{*}=\ln \left[X_{f s}\left(1-\delta_{i}\right)\right]+\eta_{f} \ln \left[\alpha_{s}+\rho\left(\tilde{N}_{b s}+\tilde{N}_{w s}\right)\right] .
$$

Suppose immigrant supply increases from 0 to $M_{s}$. The post-immigration wage is:

$$
\begin{aligned}
\ln w_{i s} & =\ln \left[X_{f s}\left(1-\delta_{i}\right)\right]+\eta_{f} \ln \left[\alpha_{s}+\rho\left(\tilde{N}_{b s}+\tilde{N}_{w s}+M_{s}\right)\right], \\
& =\ln \left[X_{f s}\left(1-\delta_{i}\right)\right]+\eta_{f} \ln \left[N_{f s}^{*}+\rho M_{s}\right], \\
& =\ln w_{i s}^{*}+\eta_{f} \rho m_{s},
\end{aligned}
$$

where $m_{s}=M_{s} / N_{f s}^{*}$, which produces the result in equation (6a). Equations (6b) and (6c) in the text follow from combining (A5) with equations (2) and (3). To derive equation (6d), write equation (5) in terms of rates of change as 


$$
\ln N_{i f s}-\ln N_{i f s}^{*}=-\frac{\theta_{i c s}}{\theta_{i f s}}\left(\ln N_{i c s}-\ln N_{i c s}^{*}\right)-\frac{\theta_{i h s}}{\theta_{i f s}}\left(\ln N_{i h s}-\ln N_{i h s}^{*}\right),
$$

where $\theta_{i c s}=N_{i c s}^{*} / \tilde{N}_{i s}, \theta_{i h s}=N_{i h s}^{*} / \tilde{N}_{i s}$, and $\theta_{i f s}=N_{i f s}^{*} / \tilde{N}_{i s}$. Equation (6d) follows after substituting equations (6b) and (6c) into (A14).

\section{Solving the state-level model}

Let $N$ be the total supply of native labor across states (assumed to be constant over time) and $M_{t}$ be the total supply of immigrants across states as of time $t$. It follows that

$$
\ln \bar{w}_{i t}=\ln w_{i}^{*}+\eta_{f} \rho m_{t}
$$

where $m_{t}=M_{t} /\left(N_{b f}^{*}+N_{w f}^{*}\right)$ is the immigrant labor supply as a share of national market employment in the pre-immigration equilibrium..$^{40}$ The native migration supply response is a lagged function of the difference between the wage in a particular state and the mean national wage given by (A15). As long as the racial discrimination parameter $\delta_{i}$ is constant across states and the supply elasticity $(\sigma)$ is the same for blacks and whites, we can write the supply function as:

$$
v_{r t}=\sigma\left(\ln w_{r, t-1}-\ln \bar{w}_{t-1}\right),
$$

where $v_{r t}=\Delta N_{r t} /\left(N_{b f r}^{*}+N_{w f r}^{*}\right)$ is the net migration rate of natives (as a share of native employment in the market sector in the pre-immigration equilibrium). For expositional convenience, we ignore the subscript indicating the particular race group in (A16) - since the wage differential between the average wage in a state and the average national wage must be the same for both race groups.

To evaluate the impact of immigration and the ensuing native migration response on state wages and sectoral employments, consider first the case in which state $r$ is hit by a one-time supply shock in period 0 of size $\bar{M}_{r}$ (with the total supply shock across states being of size $\bar{M}$ ). Following Borjas (2006), it is straightforward to show that the cumulative adjustment in the native labor supply over periods 0 to $t$ in response to this period 0 supply shock is $V_{r t}=\sum_{\tau=0}^{t} v_{r \tau}=\left[1-\left(1+\eta_{f} \rho \sigma\right)^{t}\right]\left(\widehat{m}-\widehat{m}_{r}\right)$, where we assume that $0<\left(1+\eta_{f} \rho \sigma\right)<1$, to ensure that the internal migration response of natives eventually re-equilibrates the national labor market. The variable $\bar{m}_{r}$ gives the supply of immigrants in state $r$ relative to the state native-born workforce in the pre-immigration equilibrium, and $\widehat{m}$ gives the corresponding share for the national labor market. Suppose now that the state-specific and national immigration shocks of

40 Additional assumptions sufficient for equation (A7) to hold are that log sectoral demand shifters are iid with mean zero and that any state-specific shocks to demand shifters are transitory in nature. 
size $\hat{M}_{r}$ and $\hat{M}$ occur in each period from 0 to $t$. The total resulting adjustment in the native labor force is: 41

$$
\Psi_{r t}=\sum_{\tau=0}^{t-1} V_{r \tau}=\sum_{\tau=0}^{t-1}\left[1-\left(1+\eta_{f} \rho \sigma\right)^{\tau}\right]\left(\hat{m}-\widehat{m}_{r}\right)=\left(t+\frac{1+\eta_{f} \rho \sigma}{\eta_{f} \rho \sigma}\left[1-\left(1+\eta_{f} \rho \sigma\right)^{t}\right]\right)\left(\widehat{m}-\widehat{m}_{r}\right),
$$

Equation (A17) collapses to $\eta_{f} \rho \sigma\left(m_{r}-m\right)$ if we use the approximations that $(1+x)^{t} \approx 1+x t$ and $t /(t+1) \approx 1$, where $m_{r}=(t+1) \hat{m}_{r}$ and $m=(t+1) \hat{m}$ are the immigration shares observed as of time $t$. A slight generalization of equation (A13) implies that the wage in state $r$ at time $t$ will be given by:

$$
\ln w_{i r t}=\ln w_{i}^{*}+\eta_{f} \rho\left(\Psi_{r t}+m_{r}\right)
$$

This is equivalent to equation (13a) in the text.

\section{Measurement error}

We use the simplified notation introduced in equations (16)-(18) of the text. We assume the covariance structure:

$$
\mathrm{E}\left(\pi_{R} \varepsilon_{R}\right)=\mathrm{E}\left(\pi_{R} v_{1}\right)=\mathrm{E}\left(\varepsilon_{R} v_{1}\right)=\mathrm{E}\left(\varepsilon_{R} v_{2}\right)=\mathrm{E}\left(v_{1} v_{2}\right)=0
$$

Since $p_{N}$ converges to the expected value of $\pi_{R}, v_{2}$ represents a deviation between $\pi_{R}$ and its mean, so we have $\mathrm{E}\left(p_{N} v_{2}\right)=0$, which implies that $\mathrm{E}\left(\pi_{R} v_{2}\right)=-\operatorname{var}\left(v_{2}\right) .{ }^{42}$ We adopt the following notation:

$$
\begin{aligned}
& \sigma_{1}^{2}=\operatorname{var}\left(p_{R}\right)=\operatorname{var}\left(\pi_{R}\right)+\operatorname{var}\left(v_{1}\right) \\
& \sigma_{2}^{2}=\operatorname{var}\left(p_{N}\right)=\operatorname{var}\left(\pi_{R}\right)-\operatorname{var}\left(v_{2}\right) \\
& \sigma_{12}=E\left(p_{N} p_{R}\right)=\operatorname{var}\left(\pi_{R}\right)-\operatorname{var}\left(v_{2}\right)=\sigma_{2}^{2} \\
& M_{N}=I-p_{N}\left(p_{N}^{\prime} p_{N}\right)^{-1} p_{N}^{\prime}
\end{aligned}
$$

The least squares estimates of the coefficients in the regression model that includes both state-level and national-level immigrant shares can be written as:

${ }^{41} \mathrm{We}$ assume that the period $\mathrm{t}$ immigration shock is unanticipated in period $t-1$ such that there is no anticipatory native labor migration in response to expected future immigration. To introduce anticipatory native migration into the model, one would have to specify in each period the expected sequence of expected future immigration shocks.

$42 \mathrm{We}$ are assuming that there are sufficiently large numbers of observations within each skill group so that the measurement error in the national-level immigrant share is effectively zero. With an average of over 60,000 observations per national-level skill cell, this seems reasonable. 
(A24)

$$
\begin{aligned}
\hat{\theta}_{R} & =\left[p_{R}^{\prime} M_{N} p_{R}\right]^{-1} p_{R}^{\prime} M_{N} y_{R} \\
& =\left[p_{R}^{\prime} p_{R}-p_{R}^{\prime} p_{N}\left(p_{N}^{\prime} p_{N}\right)^{-1} p_{N}^{\prime} p_{R}\right]^{-1}\left[p_{R}^{\prime} y_{R}-p_{R}^{\prime} p_{N}\left(p_{N}^{\prime} p_{N}\right)^{-1} p_{N}^{\prime} y_{R}\right]
\end{aligned}
$$

This implies that:

(A25)

$$
\begin{aligned}
\operatorname{plim} \hat{\theta}_{R} & =\frac{\sigma_{2}^{2} \operatorname{cov}\left(p_{R}, y_{R}\right)-\sigma_{12} \operatorname{cov}\left(p_{N}, y_{R}\right)}{\sigma_{1}^{2} \sigma_{2}^{2}-\sigma_{12}^{2}} \\
& =\frac{\sigma_{2}^{2} \operatorname{cov}\left(p_{R}, y_{R}\right)+\sigma_{2}^{2} \operatorname{cov}\left(p_{N}, y_{R}\right)}{\sigma_{2}^{2}\left(\sigma_{1}^{2}-\sigma_{2}^{2}\right)}
\end{aligned}
$$

Similarly,

$$
\operatorname{plim} \hat{\theta}_{N}=\frac{\sigma_{1}^{2} \operatorname{cov}\left(p_{N}, y_{R}\right)+\sigma_{2}^{2} \operatorname{cov}\left(p_{R}, y_{R}\right)}{\sigma_{2}^{2}\left(\sigma_{1}^{2}-\sigma_{2}^{2}\right)} .
$$

Evaluating the covariances yields:

$$
\begin{aligned}
\operatorname{cov}\left(p_{R}, y_{R}\right) & =E\left(p_{R}, y_{R}\right) \\
& =E\left(\pi_{R}+v_{1}\right)\left(\theta \pi_{R}+\varepsilon_{R}\right) \\
& =\theta \operatorname{var}\left(\pi_{R}\right) \\
\operatorname{cov}\left(p_{N}, y_{R}\right) & =E\left(p_{N}, y_{R}\right) \\
& =E\left(\pi_{R}+v_{2}\right)\left(\theta \pi_{R}+\varepsilon_{R}\right) \\
& =\theta\left[\operatorname{var}\left(\pi_{R}\right)-\operatorname{var}\left(v_{2}\right)\right] \\
& =\theta \sigma_{2}^{2}
\end{aligned}
$$

Equations (19a) and (19b) in the text are easily obtained by substituting these covariance terms into equations (A25) and (A26) and by using the fact that $\sigma_{1}^{2}-\sigma_{2}^{2}=\operatorname{var}\left(v_{1}\right)+\operatorname{var}\left(v_{2}\right)$. 


\section{References}

Altonji, Joseph G. and Card, David. "The Effects of Immigration on the Labor Market Outcomes of Less-Skilled Natives," in John M. Abowd and Richard B. Freeman, eds., Immigration, Trade, and the Labor Market. Chicago: University of Chicago Press, 1991, pp. 201-234.

Autor, David H., Lawrence F. Katz, and Melissa S. Kearney. "Trends in U.S. Wage Inequality: Re-Assessing the Revisionists,” Working Paper, Harvard University, 2004.

Aydemir, Abdurrahman and George J. Borjas. "Attenuation Bias in Estimating the Wage Impact of Immigration,” Working Paper, Harvard University, October 2005.

Borjas, George J. "The Labor Demand Curve Is Downward Sloping: Reexamining the Impact of Immigration on the Labor Market," Quarterly Journal of Economics 118 (November 2003): 1335-1374.

Borjas, George J. "Native Internal Migration and the Labor Market Impact of Immigration," Journal of Human Resources 41 (Spring 2006): 221-258.

Borjas, George J. "The Evolution of the Mexican-Born Workforce in the U.S. Labor Market," in George J. Borjas, editor, Mexican Immigration to the United States. Chicago: University of Chicago Press, 2007.

Bound, John and Scott Boggess. "Did Criminal Activity Increase During the 1980s? Comparisons across Data Sources," Social Science Quarterly 78 (September 1997): 725-739.

Bound, John and Richard B. Freeman. "What Went Wrong? The Erosion of Relative Earnings and Employment Among Young Black Men in the 1980s," Quarterly Journal of Economics 107 (February 1992): 201-232.

Bound, John, Michael Schoenbaum, and Timothy Waidmann. "Race and Education Differences in Disability Status and Labor Force Attachment in the Health and Retirement Survey," Journal of Human Resources 30 (Supplement 1995): S227-S267.

Butcher, Kristin F. and Anne Morrison Piehl. "Recent Immigrants: Unexpected Implications for Crime and Incarceration." Industrial and Labor Relations Review 51 (July 1998): 654-679.

Butcher, Kristin F. and Anne Morrison Piehl. "Cross-City Evidence on the Relationship between Immigration and Crime," Journal of Policy Analysis and Management 17 (Summer 1998): 457-493.

Butcher, Kristin F. and Anne Morrison Piehl. "The Role of Deportation in the Incarceration of Immigrants," in George J. Borjas, editor, Issues in the Economics of Immigration. Chicago: University of Chicago Press, 2000, pp. 351-385. 
Card, David. "Immigrant Inflows, Native Outflows, and the Local Labor Market Impacts of Higher Immigration," Journal of Labor Economics (January 2001): 22-64.

Card, David, and Thomas Lemieux. 2001. "Can Falling Supply Explain the Rising Return to College for Young Men? A Cohort-Based Analysis." Quarterly Journal of Economics May: 705-746.

Charles, Kerwin Kofi and Ming Ching Luoh. "Male Incarceration, the Marriage Market, and Female Outcomes.” Working Paper, University of Chicago, 2005.

Cortes, Patricia. 2005. "The Effects of Low-Skilled Immigration on US Prices: Evidence from CPI Data." Mimeo, MIT.

Feenstra, Robert C. Advanced International Trade. Princeton: Princeton University Press, 2004.

Fryer, Roland G., Paul S. Heaton, Steven D. Levitt, and Kevin M. Murphy. "Measuring the Impact of Crack Cocaine,” NBER Working Paper No. 11318, May 2005.

Gould, Eric D., Bruce A. Weinberg, and David B. Mustard, "Crime Rates and Local Labor Market Opportunities in the United States: 1979-1997," Review of Economics and Statistics 84 (February 2002): 45-61.

Grogger, Jeffrey. "Market Wages and Youth Crime." Journal of Labor Economics 16 (October 1998): 756-791.

Grogger, Jeffrey and Michael Willis. "The Emergence of Crack Cocaine and the Rise in Urban Crime Rates," Review of Economics and Statistics 82 (November 2000): 519-529.

Gronau, Reuben. "Leisure, Home Production, and Work: The Theory of the Allocation of Time Revisited." Journal of Political Economy 85 (December 1977): 1099-1123.

Jaeger, David. "Skill Differences and the Effect of Immigrants on the Wages of Natives," Working Paper, U.S. Bureau of Labor Statistics, 1996.

Juhn, Chinhui. "The Decline in Male Labor Market Participation: The Role of Declining Market Opportunities," Quarterly Journal of Economics 107 (February, 1992): 79-121.

Juhn, Chinhui. "Labor Market Dropouts and Trends in the Wages of Black and White Men," Industrial and Labor Relations Review 56 (July 2003): 643-662.

Juhn, Chinhui, Kevin M. Murphy, and Robert H. Topel. "Why Has the Natural Rate of Unemployment Increased Over Time?" Brookings Papers on Economic Activity (1991): 75-126.

Katz, Lawrence F., and Kevin M. Murphy. "Changes in the Wage Structure, 1963-87: Supply and Demand Factors," Quarterly Journal of Economics 107 (February 1992): 35-78. 
Machin, Stephen and Costas Meghir. "Crime and Economic Incentives," Journal of Human Resources 39 (Fall 2004): 958-979.

Ottaviano, Gianmarco I.P., and Giovanni Peri. 2006. "Rethinking the Effects of Immigration on Wages." NBER Working Paper No. 12497.

Parsons, Donald O. "Racial Trends in Male Labor Force Participation," American Economic Review 70 (December 1980): 911-920.

Raphael, Steven and Michael A. Stoll (2005), "The Effect of Prison Releases on Regional Crime Rates," in William G. Gale and Janet Rothenberg Pack (eds.), The Brookings-Wharton Papers on Urban Economics Affairs, Volume 5, The Brookings Institution: Washington, D.C.

Raphael, Stephen and Lucas Ronconi. "Reconciling National and Regional Estimates of the Effects of Immigration on U.S. Labor Markets: The Confounding Effects of Native Male Incarceration Trends," Working Paper, University of California, Berkeley, 2005.

Stern, Steven. "Measuring the Effect of Disability on Labor Force Participation," Journal of Human Resources 24 (Summer 1989): 361-395.

Venkatesh, Sudhir Alladi, "The Social Organization of Street Crime Activity in an Urban Ghetto." American Journal of Sociology 103 (July 1997): 82-111.

Welch, Finis. "The Employment of Black Men," Journal of Labor Economics 8 (January 1990): S26-S74.

Western, Bruce and Becky Pettit. "Incarceration and Racial Inequality in Men's Employment," Industrial and Labor Relations Review 54 (October 2000): 3-16. 
Figure 1. The share of immigrants in the workforce




Figure 2. Trends in employment rates, by race, education and experience

\section{A. Blacks}

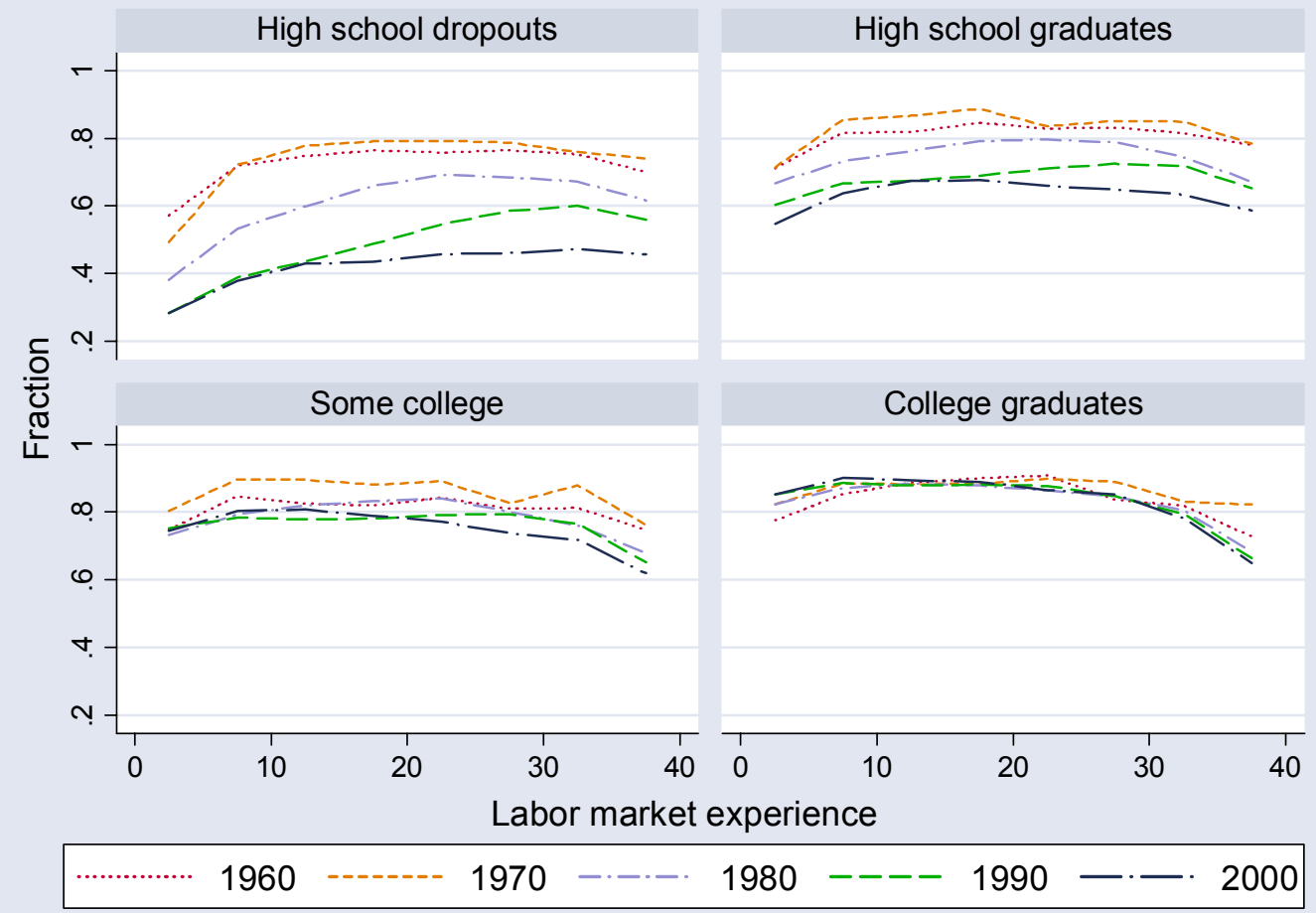

\section{B. Whites}




Figure 3. Trends in incarceration rates, by race, education and experience

\section{A. Blacks}

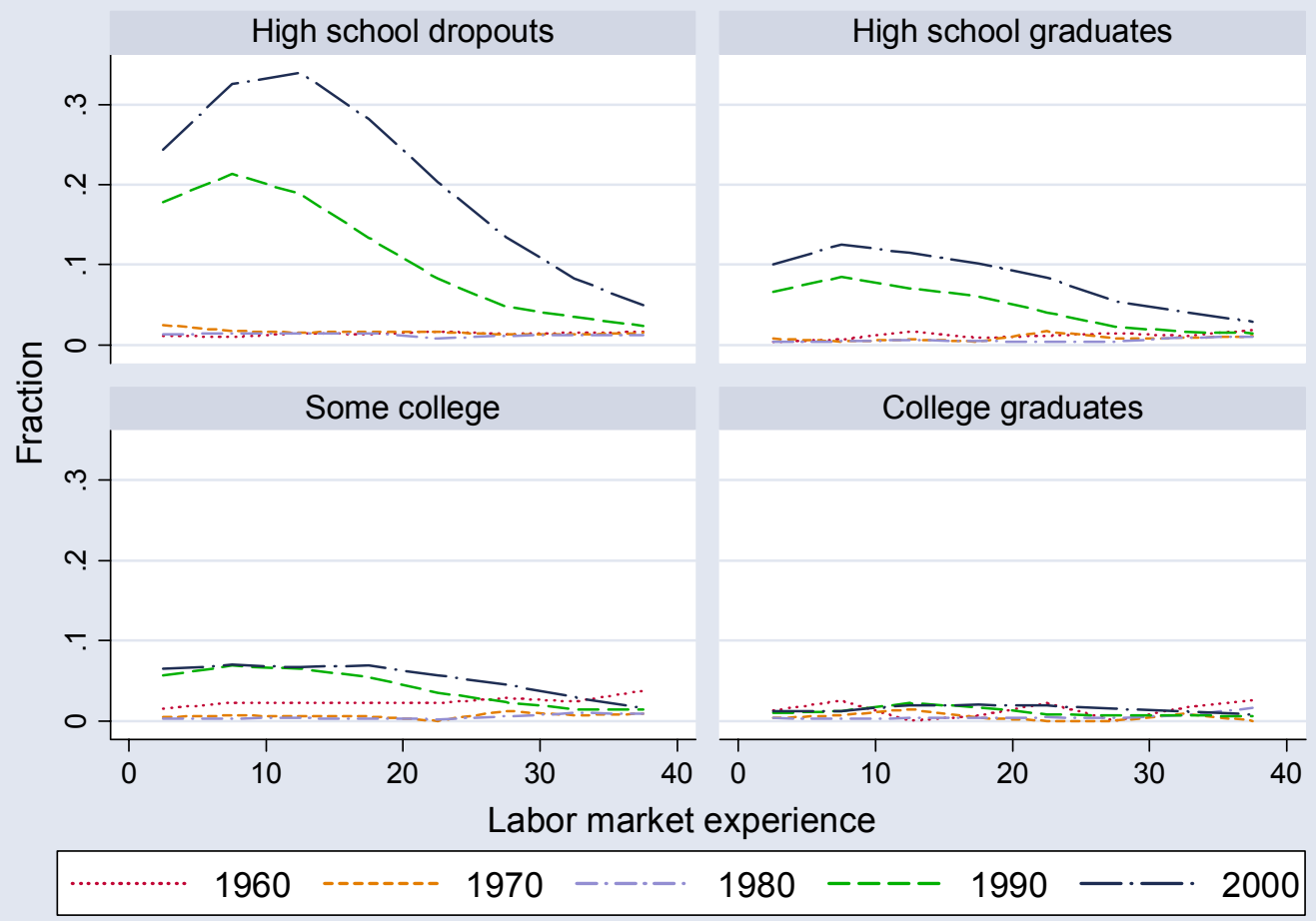

\section{B. Whites}

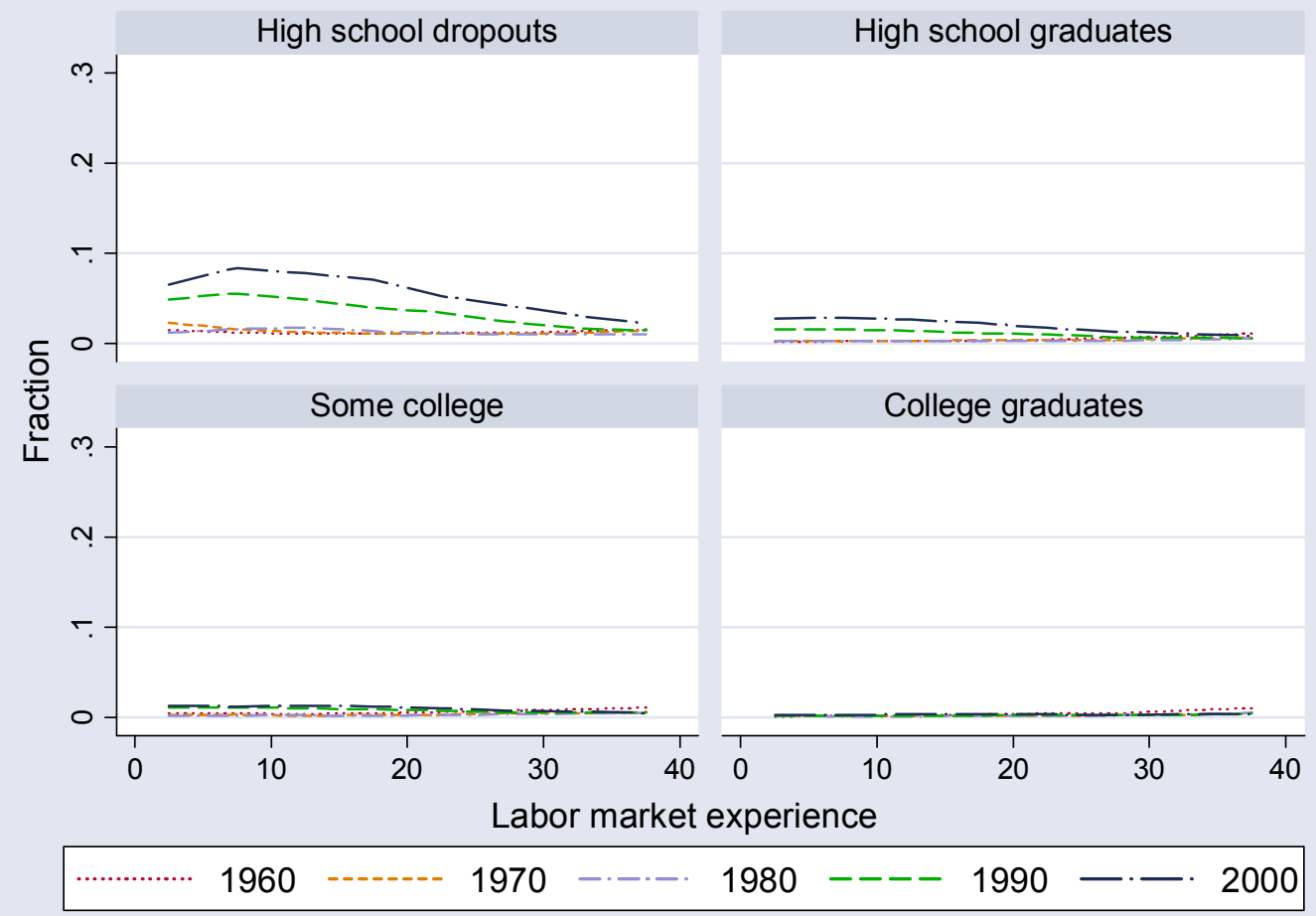


Figure 4. Relation between decadal changes in employment and immigration (removing decade effects)

\section{A. Blacks}

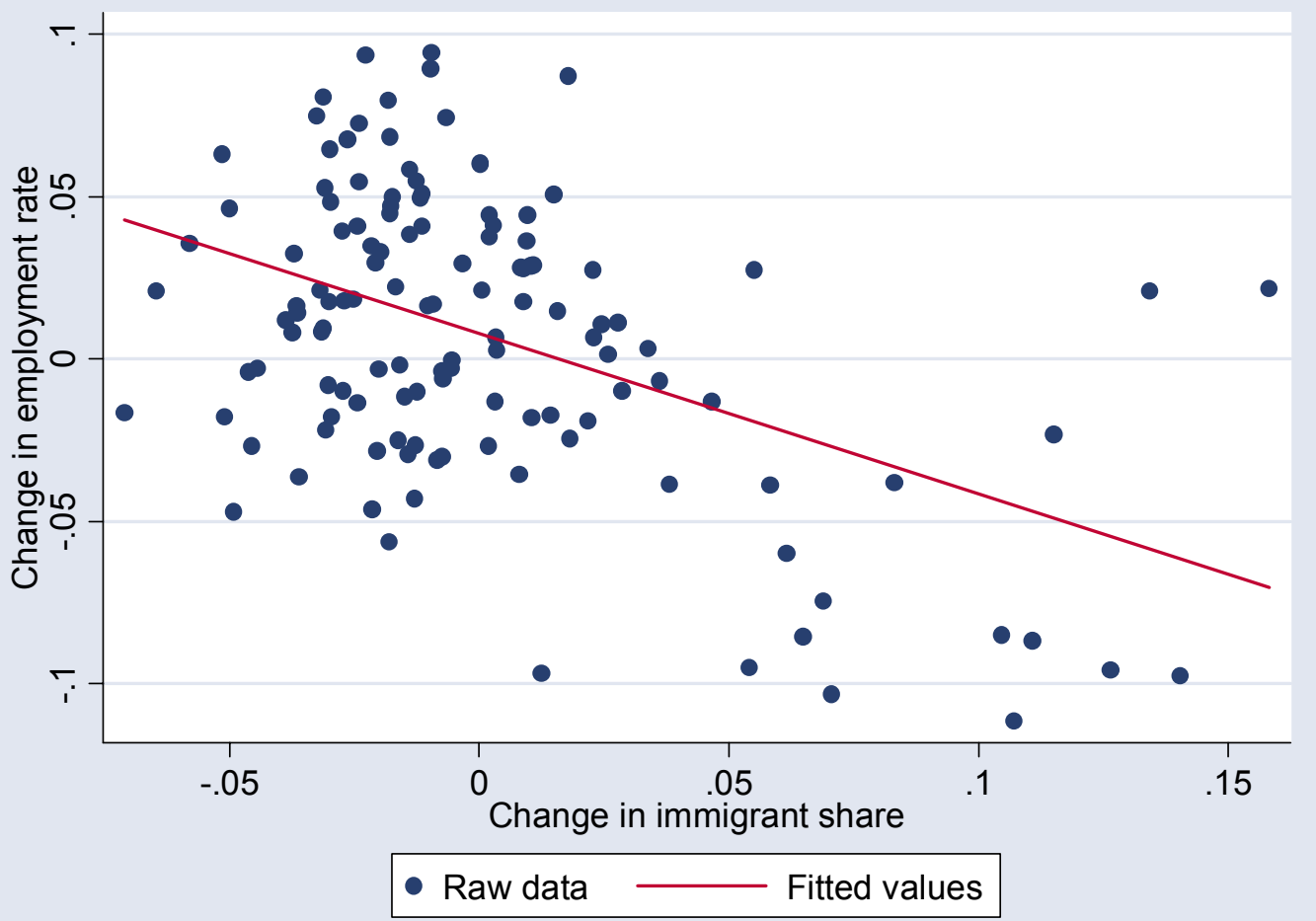

\section{B. Whites}

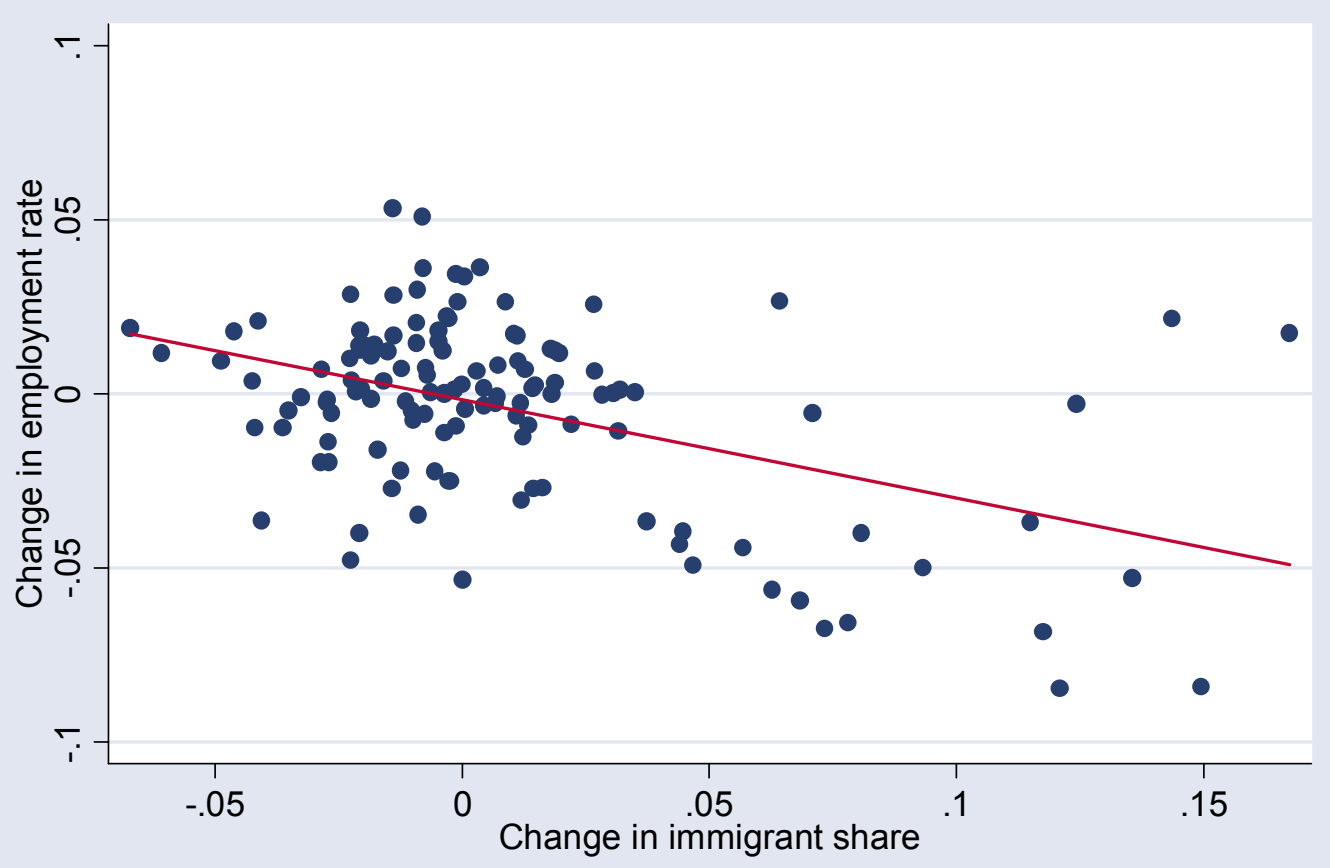

- Raw data Fitted values 
Figure 5. Relation between decadal changes in incarceration and immigration

A. Blacks (removing decade effects)

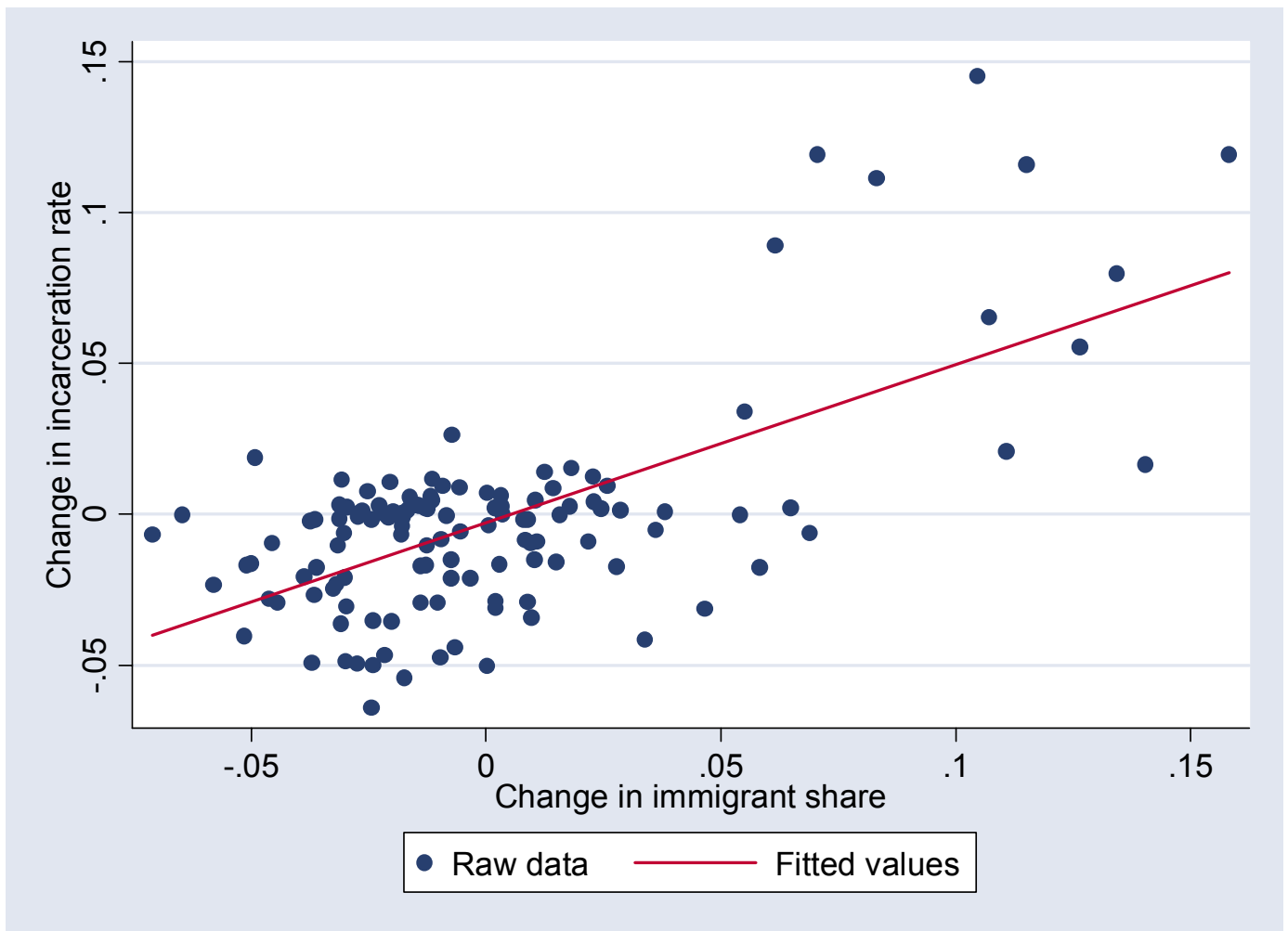

\section{B. Whites}



- Raw data Fitted values 
Figure 6. Initial equilibrium: allocation of labor across sectors

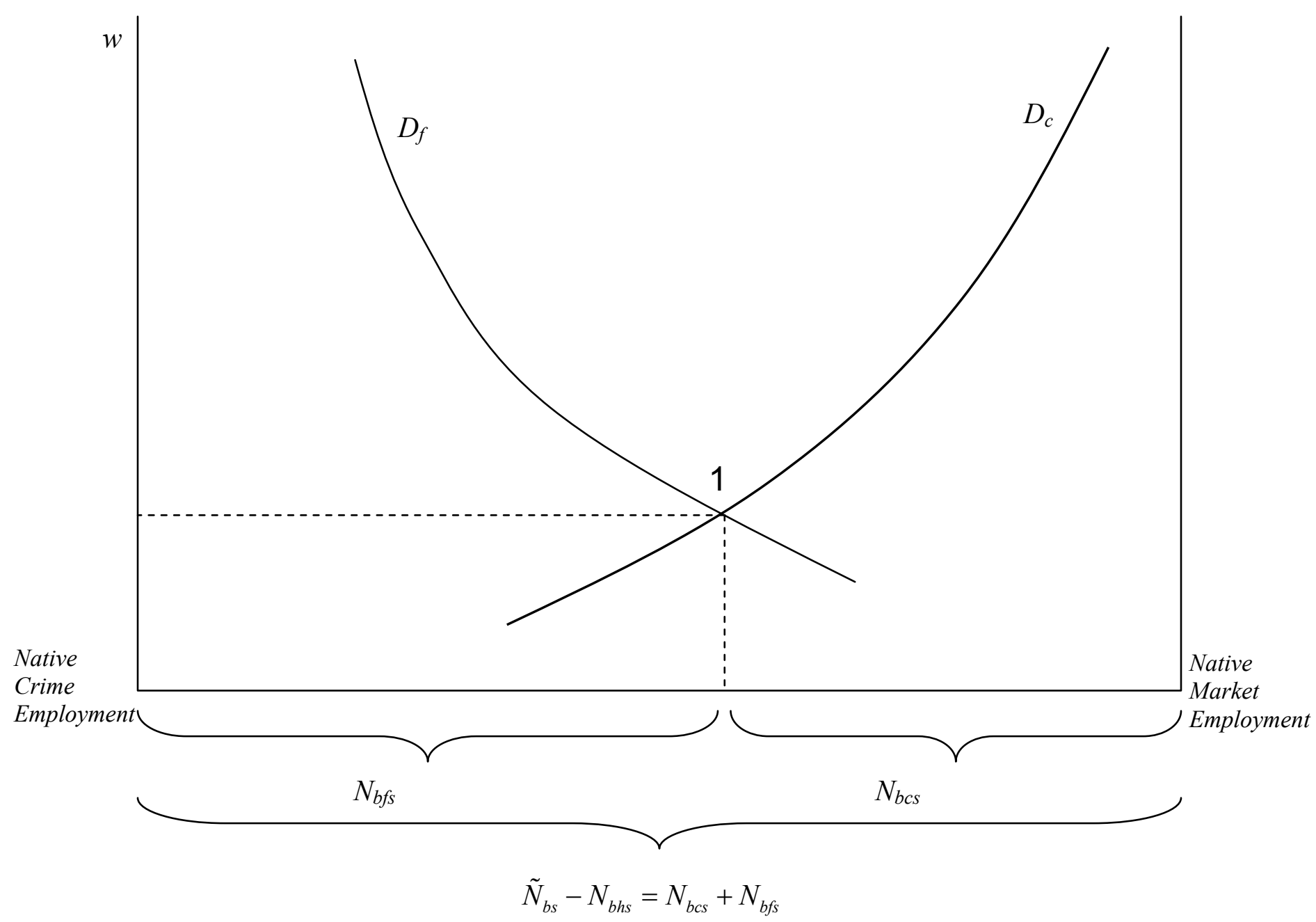


Figure 7. Impact of immigration on sectoral allocation of labor

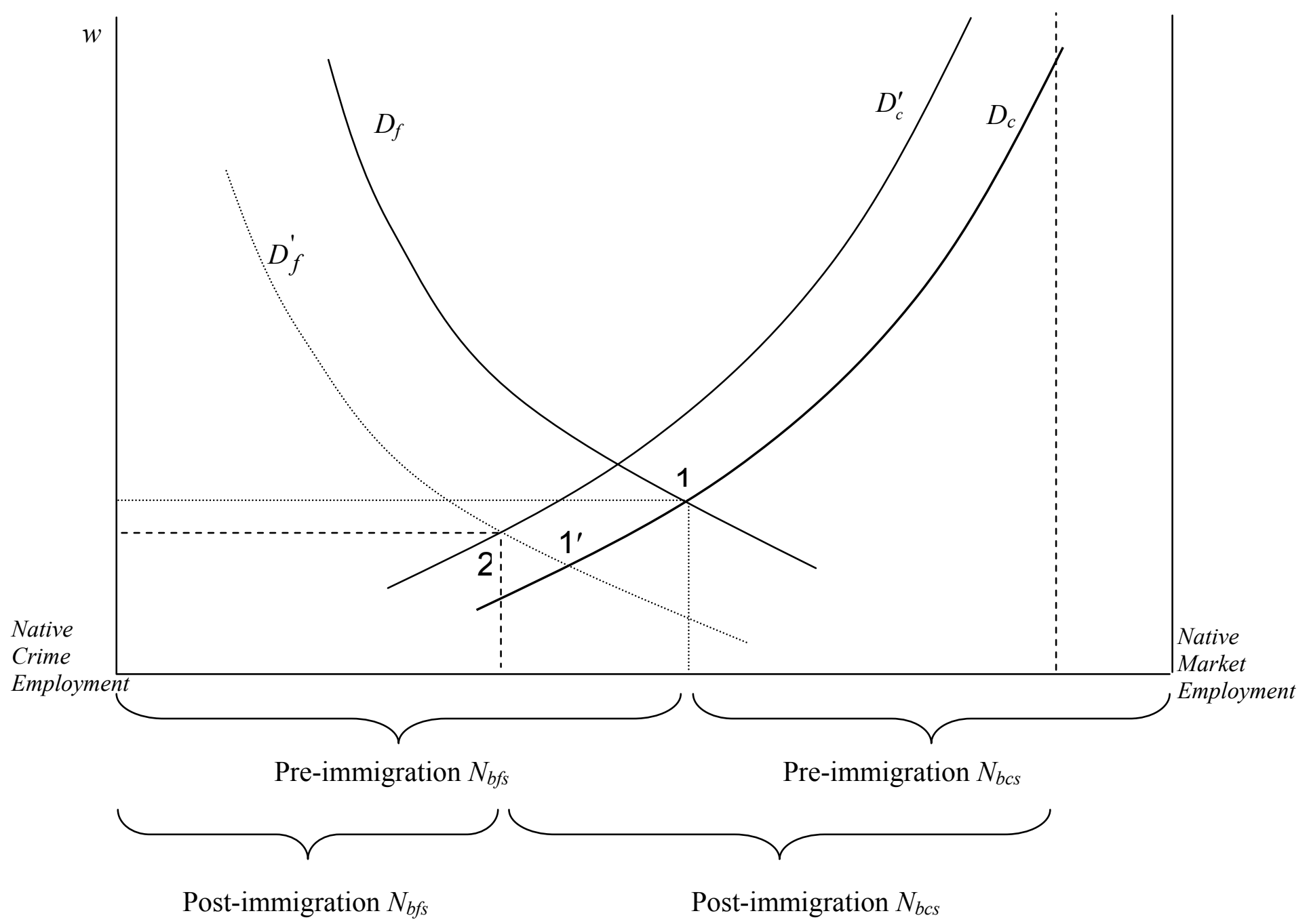




\section{Table 1. Tests for perfect substitution}

Specification

123

34

A. Testing perfect substitution between black and white native workers.

Estimate of $-1 / \sigma$

0.007

$-0.006$

0.018

$-0.053$

$(0.010)$

(0.007)

(0.037)

(0.041)

Includes time fixed effects

Includes education-experience fixed effects

No

Yes

Yes

Yes

No

No

Yes

Yes

No

No

No

Yes

Interacts experience and time fixed effects

No

No

No

Yes

A. Testing perfect substitution between immigrant and native workers

Estimate of $-1 / \sigma$

0.024

0.019

0.050

(0.008)

(0.008)

(0.015)

(0.045)

Includes time fixed effects

Includes education-experience fixed effects

$\begin{array}{lr}\text { No } & \text { Yes } \\ \text { No } & \text { No } \\ \text { No } & \text { No } \\ \text { No } & \text { No }\end{array}$

Yes

Yes

Interacts education and time fixed effects

Interacts experience and time fixed effects

No

No

Yes

Yes

Yes

No Yes

Notes: Standard errors are reported in parentheses and are adjusted for clustering within education-experience cells. All regressions have 160 observations and are weighted by the total number of observations used to calculate the dependent variable. The dependent variable in panel A is the difference between the mean log weekly wage of black and white workers, and the independent variable is the difference between the log of the number of black workers and the $\log$ of the number of white workers. The dependent variable in panel B is the difference between the mean $\log$ weekly wage of immigrant and native workers, and the independent variable is the difference between the $\log$ of the number of immigrant workers and the log of the number of native workers. 


\section{Table 2. National level estimates of the impact of immigration}

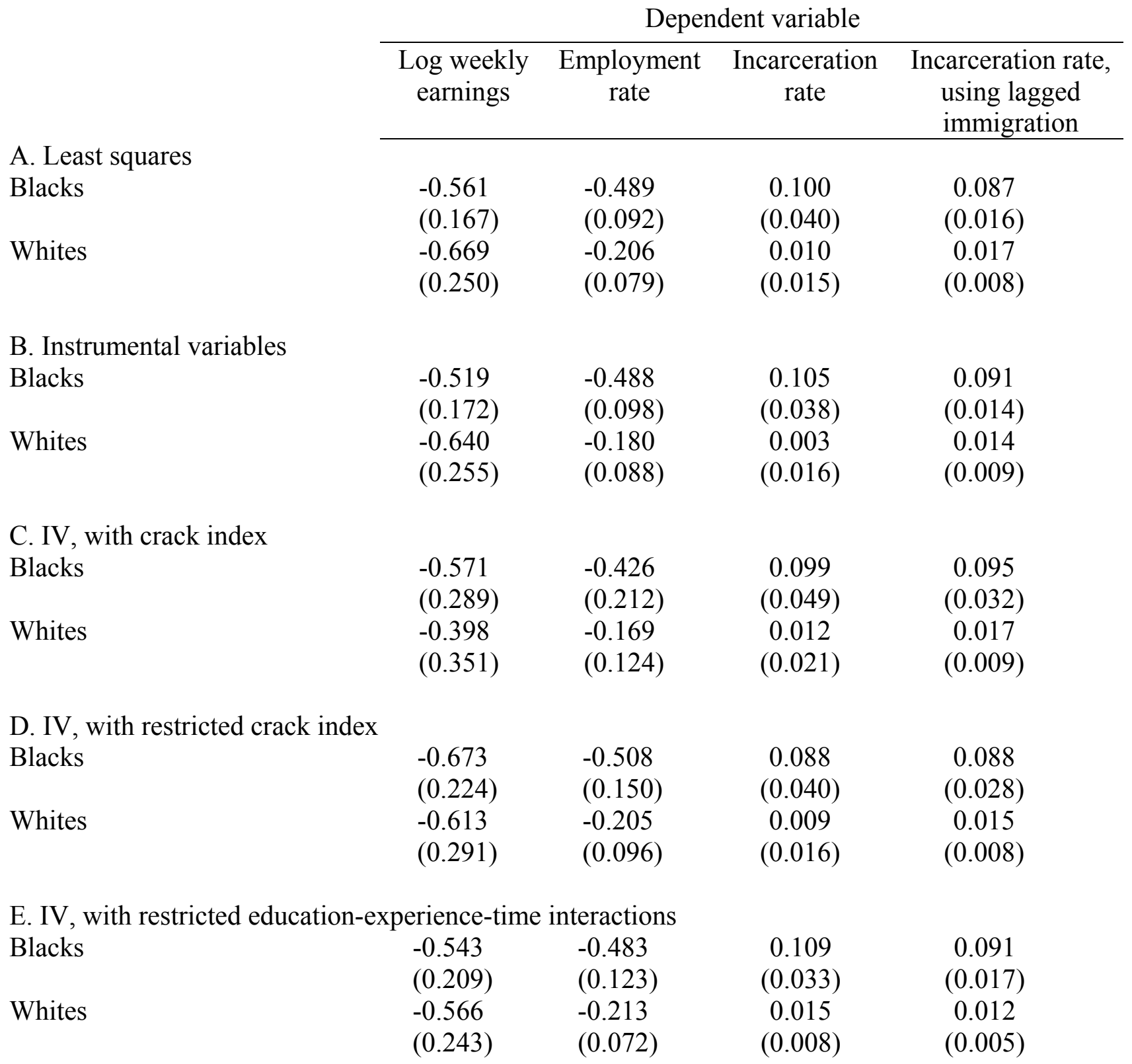

Notes: Standard errors are reported in parentheses and are adjusted for clustering within education-experience cells. All regressions have 160 observations and include education, experience, and period fixed effects, and interactions between education and experience fixed effects, education and period fixed effects, and experience and period fixed effects. Regressions on employment and incarceration rates use a grouped logit specification; reported coefficients are marginal effects evaluated at the mean employment and incarceration rates in the particular sample. Instrumental variable regressions instrument the immigrant share in the workforce with the immigrant share in the population. The restricted crack index sets the value of the Fryer et al (2005) crack index to zero if the skill cell has at least a high school education or more than 20 years of experience. The restricted education-experience-time interactions include a vector of fixed effects indicating if the cell refers to a post-1980 observation of high school dropouts with $1-10,11-20$, or more than 20 years of experience; a post-1980 observation of workers with a high school diploma or some college with 1-10,11-20, or more than 20 years of experience; or a post-1980 observation of college graduates with 1-10, 11-20, or more than 20 years of experience. The lagged immigration variable gives the immigrant share for the particular skill group measured five years prior to the Census. 


\section{Table 3. State-level estimates of the wage impact of immigration}

\section{A. Least squares \\ Model 1}

Model 2

\begin{tabular}{ccc}
\multicolumn{3}{c}{ Blacks } \\
\hline $\begin{array}{c}\text { State } \\
\text { share }\end{array}$ & National & \\
share & Sum \\
\hline
\end{tabular}

$-0.266$

$(0.063)$

$-0.246$

(0.138)

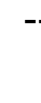

Sum

(0.138)

$-0.697$

(0.155)

\begin{tabular}{ccc}
\multicolumn{3}{c}{ Whites } \\
\hline State & National \\
share & share & Sum \\
\hline
\end{tabular}

B. Instrumental variables

Model 1

Model 2

-0.258
$(0.064)$

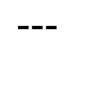

$-0.239$

$-0.415$

(0.185)

(0.064)

$-0.654$

(0.188)



-0.168
$(0.036)$

$-0.192$

(0.031)

$-0.152$

(0.035)

$-0.639$

$-0.790$

(0.229)

(0.222)

C. IV, with crack index

Model 1

$$
-0.266
$$

Model 2

$$
-0.259
$$

$-0.332$

(0.199)

$-0.591$

(0.204)

$-0.126$

$-0.644$

$-0.771$

(0.035)

(0.102)

(0.104)

(0.063)

(0.199)

(0.204)

-0.136
$(0.035)$

$-0.119$

$-0.394$

(0.036)

(0.111)

$-0.513$

(0.109)

D. IV, with restricted crack index

Model 1

$$
-0.257
$$

(0.064)

Model 2

$-0.245$

(0.064)

$\begin{array}{ll}-0.488 & -0.732 \\ (0.190) & (0.195)\end{array}$

$-0.149$

(0.035)

$-0.124$

(0.035)

$-0.595$

$-0.718$

(0.103)

(0.105)

E. IV, with restricted education-experience-time interactions

Model 1

Model 2

$$
\begin{aligned}
& -0.253 \\
& (0.064)
\end{aligned}
$$$$
-0.238
$$

(0.064)

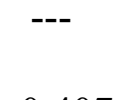

$-0.407$

(0.196)

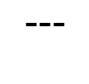

$-0.645$

(0.201)
$-0.158$

(0.035)

$-0.129$

(0.035)
$-0.524$

$(0.105)$

Notes: Standard errors are reported in parentheses and are adjusted for clustering within state-skill cells. The regressions for blacks have 6,581 observations; the regressions for whites have 8,153 observations. All regressions include education, experience, state, and period fixed effects, two-way interactions between education and period, experience and period, and state and period fixed effects, and three-way interactions between education, experience, and state fixed effects. Model 1 instruments the state-level immigrant share in the workforce with the state-level population share. Model 2 instruments the state- and national-level immigrant shares in the workforce with the stateand national-level population shares. The restricted crack index sets the value of the Fryer et al (2005) crack index to zero if the skill cell has at least a high school education or more than 20 years of experience. The restricted education-experience-time interactions include a vector of fixed effects indicating if the cell refers to a post-1980 observation of high school dropouts with 1-10,11-20, or more than 20 years of experience; a post-1980 observation of workers with a high school diploma or some college with 1-10, 11-20, or more than 20 years of experience; or a post-1980 observation of college graduates with 1-10, 11-20, or more than 20 years of experience. 


\section{Table 4. State-level estimates of the impact of immigration on sectoral allocation}

\begin{tabular}{|c|c|c|c|c|c|c|c|c|c|}
\hline & \multicolumn{3}{|c|}{ Employment rate } & \multicolumn{3}{|c|}{ Incarceration rate } & \multicolumn{3}{|c|}{$\begin{array}{c}\text { Incarceration rate (with } \\
\text { lagged immigration) }\end{array}$} \\
\hline & $\begin{array}{l}\text { State } \\
\text { share }\end{array}$ & $\begin{array}{l}\text { National } \\
\text { share }\end{array}$ & Sum & $\begin{array}{l}\text { State } \\
\text { share }\end{array}$ & $\begin{array}{l}\text { National } \\
\text { share }\end{array}$ & Sum & $\begin{array}{l}\text { State } \\
\text { share }\end{array}$ & $\begin{array}{l}\text { National } \\
\text { share }\end{array}$ & Sum \\
\hline \multicolumn{10}{|c|}{ A. Least squares } \\
\hline Blacks & $\begin{array}{l}-0.068 \\
(0.021)\end{array}$ & $\begin{array}{l}-0.254 \\
(0.062)\end{array}$ & $\begin{array}{l}-0.322 \\
(0.059)\end{array}$ & $\begin{array}{r}0.008 \\
(0.016)\end{array}$ & $\begin{array}{c}0.099 \\
(0.053)\end{array}$ & $\begin{array}{c}0.108 \\
(0.052)\end{array}$ & $\begin{array}{r}0.029 \\
(0.021)\end{array}$ & $\begin{array}{c}0.080 \\
(0.042)\end{array}$ & $\begin{array}{r}0.109 \\
(0.038)\end{array}$ \\
\hline Whites & $\begin{array}{l}-0.058 \\
(0.009)\end{array}$ & $\begin{array}{l}-0.181 \\
(0.027)\end{array}$ & $\begin{array}{l}-0.239 \\
(0.028)\end{array}$ & $\begin{array}{r}0.000 \\
(0.002)\end{array}$ & $\begin{array}{c}0.014 \\
(0.008)\end{array}$ & $\begin{array}{c}0.014 \\
(0.008)\end{array}$ & $\begin{array}{r}0.004 \\
(0.003)\end{array}$ & $\begin{array}{c}0.015 \\
(0.007)\end{array}$ & $\begin{array}{r}0.019 \\
(0.007)\end{array}$ \\
\hline \multicolumn{10}{|c|}{ B. Instrumental variables } \\
\hline Blacks & $\begin{array}{l}-0.058 \\
(0.021)\end{array}$ & $\begin{array}{l}-0.257 \\
(0.065)\end{array}$ & $\begin{array}{l}-0.315 \\
(0.061)\end{array}$ & $\begin{array}{r}0.003 \\
(0.016)\end{array}$ & $\begin{array}{c}0.100 \\
(0.054)\end{array}$ & $\begin{array}{c}0.103 \\
(0.054)\end{array}$ & $\begin{array}{r}0.022 \\
(0.021)\end{array}$ & $\begin{array}{c}0.085 \\
(0.042)\end{array}$ & $\begin{array}{r}0.107 \\
(0.040)\end{array}$ \\
\hline Whites & $\begin{array}{l}-0.050 \\
(0.009)\end{array}$ & $\begin{array}{l}-0.160 \\
(0.028)\end{array}$ & $\begin{array}{l}-0.210 \\
(0.029)\end{array}$ & $\begin{array}{r}-0.001 \\
(0.002)\end{array}$ & $\begin{array}{c}0.008 \\
(0.008)\end{array}$ & $\begin{array}{c}0.007 \\
(0.008)\end{array}$ & $\begin{array}{r}0.003 \\
(0.003)\end{array}$ & $\begin{array}{c}0.014 \\
(0.007)\end{array}$ & $\begin{array}{r}0.016 \\
(0.007)\end{array}$ \\
\hline \multicolumn{10}{|c|}{ C. IV, with crack index } \\
\hline Blacks & $\begin{array}{l}-0.061 \\
(0.022)\end{array}$ & $\begin{array}{l}-0.275 \\
(0.078)\end{array}$ & $\begin{array}{l}-0.336 \\
(0.075)\end{array}$ & $\begin{array}{r}0.009 \\
(0.018)\end{array}$ & $\begin{array}{c}0.118 \\
(0.066)\end{array}$ & $\begin{array}{c}0.127 \\
(0.064)\end{array}$ & $\begin{array}{r}0.028 \\
(0.022)\end{array}$ & $\begin{array}{c}0.079 \\
(0.054)\end{array}$ & $\begin{array}{r}0.107 \\
(0.050)\end{array}$ \\
\hline Whites & $\begin{array}{l}-0.050 \\
(0.009)\end{array}$ & $\begin{array}{l}-0.135 \\
(0.028)\end{array}$ & $\begin{array}{l}-0.185 \\
(0.029)\end{array}$ & $\begin{array}{r}-0.002 \\
(0.002)\end{array}$ & $\begin{array}{c}0.017 \\
(0.010)\end{array}$ & $\begin{array}{c}0.014 \\
(0.010)\end{array}$ & $\begin{array}{r}0.001 \\
(0.003)\end{array}$ & $\begin{array}{c}0.015 \\
(0.008)\end{array}$ & $\begin{array}{r}0.016 \\
(0.008)\end{array}$ \\
\hline \multicolumn{10}{|c|}{ D. IV, with restricted crack } \\
\hline Blacks & $\begin{array}{l}-0.058 \\
(0.021)\end{array}$ & $\begin{array}{l}-0.271 \\
(0.068)\end{array}$ & $\begin{array}{l}-0.329 \\
(0.065)\end{array}$ & $\begin{array}{r}0.007 \\
(0.016)\end{array}$ & $\begin{array}{c}0.119 \\
(0.057)\end{array}$ & $\begin{array}{c}0.126 \\
(0.057)\end{array}$ & $\begin{array}{r}0.025 \\
(0.021)\end{array}$ & $\begin{array}{c}0.095 \\
(0.044)\end{array}$ & $\begin{array}{r}0.121 \\
(0.041)\end{array}$ \\
\hline Whites & $\begin{array}{l}-0.052 \\
(0.009)\end{array}$ & $\begin{array}{l}-0.201 \\
(0.030)\end{array}$ & $\begin{array}{l}-0.253 \\
(0.031)\end{array}$ & $\begin{array}{r}-0.000 \\
(0.002)\end{array}$ & $\begin{array}{c}0.012 \\
(0.008)\end{array}$ & $\begin{array}{c}0.011 \\
(0.008)\end{array}$ & $\begin{array}{r}0.002 \\
(0.003)\end{array}$ & $\begin{array}{c}0.017 \\
(0.007)\end{array}$ & $\begin{array}{r}0.019 \\
(0.007)\end{array}$ \\
\hline \multicolumn{10}{|c|}{ E. IV, with restricted education-experience-time interactions } \\
\hline Blacks & $\begin{array}{l}-0.056 \\
(0.021)\end{array}$ & $\begin{array}{c}-0.262 \\
(0.066)\end{array}$ & $\begin{array}{l}-0.319 \\
(0.064)\end{array}$ & $\begin{array}{r}0.003 \\
(0.017)\end{array}$ & $\begin{array}{c}0.107 \\
(0.058)\end{array}$ & $\begin{array}{c}0.111 \\
(0.057)\end{array}$ & $\begin{array}{r}0.022 \\
(0.021)\end{array}$ & $\begin{array}{c}0.078 \\
(0.047)\end{array}$ & $\begin{array}{r}0.100 \\
(0.044)\end{array}$ \\
\hline Whites & $\begin{array}{c}-0.049 \\
(0.009)\end{array}$ & $\begin{array}{l}-0.188 \\
(0.029)\end{array}$ & $\begin{array}{l}-0.237 \\
(0.029)\end{array}$ & $\begin{array}{r}-0.002 \\
(0.002)\end{array}$ & $\begin{array}{c}0.019 \\
(0.008)\end{array}$ & $\begin{array}{c}0.017 \\
(0.008)\end{array}$ & $\begin{array}{r}0.002 \\
(0.003)\end{array}$ & $\begin{array}{c}0.013 \\
(0.008)\end{array}$ & $\begin{array}{r}0.014 \\
(0.007)\end{array}$ \\
\hline
\end{tabular}

Notes: Standard errors are reported in parentheses and are adjusted for clustering within state-skill cells. The numbers of observations in the regressions vary due to empty cells. For blacks (whites), the employment and incarceration regressions have 6,357 and 3,052 (8,152 and 5,457) observations, respectively. All regressions include education, experience, state, and period fixed effects, two-way interactions between education and period, experience and period, and state and period fixed effects, and three-way interactions between education, experience, and state fixed effects. Regressions on employment and incarceration rates use a grouped logit specification; reported coefficients are marginal effects evaluated at the mean employment and incarceration rates in the particular sample. IV regressions instrument state- and national-level immigrant shares in the workforce with the state- and national-level population shares. The restricted crack index sets the value of the Fryer et al (2005) crack index to zero if the skill cell has at least a high school education or more than 20 years of experience. The restricted education-experience-time interactions include a vector of fixed effects indicating if the cell refers to a post-1980 observation of high school dropouts with 1-10,11-20, or more than 20 years of experience; a post-1980 observation of workers with a high school diploma or some college with 1-10,11-20, or more than 20 years of experience; or a post-1980 observation of college graduates with 1-10,11-20, or more than 20 years of experience. The lagged immigration variables gives the immigrant share for the particular skill group measured five years prior to the Census both at the state and national levels. 
Table 5. The impact of the 1980-2000 immigrant influx

Blacks:

National-level analysis

State-level analysis

\begin{tabular}{ccccc}
\cline { 2 - 4 } $\begin{array}{c}\text { 1. Actual change } \\
(1980-2000)\end{array}$ & $\begin{array}{c}\text { 2. Predicted } \\
\text { impact }\end{array}$ & $\begin{array}{c}3 . \% \text { due to } \\
\text { immigration }\end{array}$ & $\begin{array}{c}\text { 4. Predicted } \\
\text { impact }\end{array}$ & $\begin{array}{c}5 . \% \text { due to } \\
\text { immigration }\end{array}$ \\
\hline
\end{tabular}

Log weekly wage

High school dropouts

$\begin{array}{rrrrr}-0.140 & -0.083 & 59.5 & -0.099 & 70.7 \\ -0.085 & -0.032 & 37.4 & -0.038 & 44.4 \\ 0.008 & -0.033 & -417.2 & -0.040 & -495.6 \\ 0.127 & -0.044 & -34.7 & -0.052 & -41.2 \\ -0.060 & -0.036 & 60.0 & -0.043 & 72.0 \\ & & & & \\ -0.179 & -0.074 & 41.3 & -0.049 & 27.3 \\ -0.098 & -0.028 & 28.9 & -0.019 & 19.1 \\ -0.022 & -0.030 & 137.9 & -0.020 & 91.1 \\ 0.006 & -0.039 & -617.3 & -0.026 & -407.7 \\ -0.097 & -0.032 & 33.0 & -0.021 & 21.6 \\ & & & & \\ 0.199 & 0.017 & 8.4 & 0.017 & 8.5 \\ 0.084 & 0.006 & 7.6 & 0.007 & 7.8 \\ 0.054 & 0.007 & 12.5 & 0.007 & 12.8 \\ 0.011 & 0.009 & 77.6 & 0.009 & 79.0 \\ 0.106 & 0.007 & 6.6 & 0.007 & 6.6\end{array}$

Whites:

Log weekly wage

High school dropouts

$-0.206$

$-0.086$

41.7

$-0.099$

48.1

High school graduates

$-0.033$

22.8

$-0.038$

26.4

Some college

$-0.050$

70.3

$-0.041$

81.2

College graduates

$-0.046$

$-45.2$

$-0.053$

$-52.2$

All persons

$-0.060$

$-0.037$

61.7

$-0.042$

70.0

Employment rate

High school dropouts

$-0.102-0.032$

31.6

$-0.036$

35.2

High school graduates

$-0.013$

26.9

$-0.014$

29.9

$-0.015 \quad-0.013$

90.2

$-0.015$

100.4

College graduates

$-0.008$

$-0.017$

215.8

$-0.019$

240.1

$-0.038$

$-0.014$

$-0.015$

39.5

Incarceration rate

High school dropouts

0.043

0.002

0.003

6.0

0.017

0.001

5.3

0.001

5.9

Some college

0.001

5.2
12.5

0.001

14.2

0.001

0.001

99.2

0.001

112.5

All persons

0.015

0.001

6.7

0.001

6.7

Notes: The education-specific immigrant supply shock is defined as the number of immigrants arriving between 1980 and 2000 divided by a baseline population equal to the average size of the native workforce (over 1980-2000) plus the number of immigrants in 1980. The education-specific supply shocks are: 0.210 for high school dropouts; 0.080 for high school graduates; 0.084 for persons with some college; 0.111 for college graduates; and 0.092 for all persons. The predicted impacts use national-level coefficient reported in Panel E of Table 2, and the sum of the state-level and national-level coefficients reported in Panel E of Tables 3 and 4. The changes for "all persons" are calculated using fixed weights equal to the average of the 1980 and 2000 race-specific education distributions. 